\title{
The MT2 receptor stimulates axonogenesis and enhances synaptic transmission by activating Akt signaling
}

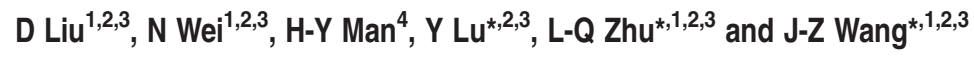

The MT2 receptor is a principal type of G protein-coupled receptor that mainly mediates the effects of melatonin. Deficits of melatonin/MT2 signaling have been found in many neurological disorders, including Alzheimer's disease, the most common cause of dementia in the elderly, suggesting that preservation of the MT2 receptor may be beneficial to these neurological disorders. However, direct evidence linking the MT2 receptor to cognition-related synaptic plasticity remains to be established. Here, we report that the MT2 receptor, but not the MT1 receptor, is essential for axonogenesis both in vitro and in vivo. We find that axon formation is retarded in MT2 receptor knockout mice, MT2-shRNA electroporated brain slices or primary neurons treated with an MT2 receptor selective antagonist. Activation of the MT2 receptor promotes axonogenesis that is associated with an enhancement in excitatory synaptic transmission in central neurons. The signaling components downstream of the MT2 receptor consist of the Akt/GSK-3 $\beta /$ CRMP-2 cascade. The MT2 receptor C-terminal motif binds to Akt directly. Either inhibition of the MT2 receptor or disruption of MT2 receptor-Akt binding reduces axonogenesis and synaptic transmission. Our data suggest that the MT2 receptor activates Akt/GSK-3 $\beta /$ CRMP-2 signaling and is necessary and sufficient to mediate functional axonogenesis and synaptic formation in central neurons.

Cell Death and Differentiation (2015) 22, 583-596; doi:10.1038/cdd.2014.195; published online 12 December 2014

Synaptic circuits are established at the sites of axon-dendritic, axon-somatic or axon-axonal contact, in which functional axonogenesis is a critical step. ${ }^{1}$ Axonogenesis can be regulated by many intracellular signals that involve cytoskeletal rearrangements, ${ }^{2}$ local protein degradation, ${ }^{3}$ as well as diffusional barriers. ${ }^{4}$ Additionally, several extracellular neurotrophic factors and hormones have also been shown to have a role in axon guidance and synaptic formation in central neurons. ${ }^{5,6}$ To date, the role of melatonin and its receptors in axonogenesis remains unclear. Most of the biological functions of melatonin are mediated by its two receptors, MT1 and MT2 receptors, both of them belong to the $G$ protein-coupled receptor (GPCR) subfamily and are widely expressed throughout the central nervous system (CNS). ${ }^{7}$ Activation of the MT2 receptor in response to melatonin is critical for controlling circadian rhythms ${ }^{7}$ and regulation of slow wave sleep. $^{8,9}$ Early studies have shown that activation of the MT2 receptor in the retina reduces the release of dopamine, while dopamine inhibits growth cone motility and neurite outgrowth during embryonic development, ${ }^{10,11}$ suggesting the involvement of the MT2 receptor in functional axonogenesis. In mutant mice with deficient expression of the MT2 gene, the induction of long-term potentiation (LTP) of excitatory synaptic transmission is impaired, and this impairment is closely related to deficits in learning. ${ }^{12}$ In the hippocampus, the MT2 receptor inhibits $\mathrm{GABA}_{\mathrm{A}}$ receptor-mediated current, ${ }^{13}$ which is implicated in the synaptic transmission. In Alzheimer's disease, expression of the MT2 receptor is significantly reduced, especially in the hippocampus. ${ }^{12,14,15} \mathrm{~A}$ partial agonist of the MT2 receptor, UCM765, exhibits anxiolytic-like properties by increasing the time spent in the open arm of an elevated plus maze test, and by reducing the latency to eat in a novel environment in the novelty suppressed feeding test, suggesting its role in anxiety. ${ }^{16}$ Together, these findings suggest that the MT2 receptor links the signaling cascades that mediate learning and memory formation, one of the important biological functions of melatonin; ${ }^{17}$ however, the cellular and molecular events underlying this linkage are yet to be established.

Dissociated hippocampal neurons have been commonly used as an excellent in vitro model in the study of axon development and synaptic transmission because they maintain morphological, functional and molecular characteristics of the hippocampal neurons in vivo. ${ }^{18}$ In dissociated hippocampal neurons, the transition for axon formation and maturation involves the following five stages: ${ }^{19}$ stage 1 neurons $(\sim 2$ to $4 \mathrm{~h}$ after plating) display abundant lamellipodia and filopodia that develop into several immature short neurites at stage 2

\footnotetext{
${ }^{1}$ Department of Pathophyiology, School of Basic Medicine, Tongji Medical College, Huazhong University of Science and Technology, Wuhan 430030, China; ${ }^{2}$ Sino-Canada Collaborative Platform on Molecular Biology of Neurological Disease, Key Laboratory of Neurological Diseases, Ministry of Education, Tongji Medical College, Huazhong University of Science and Technology, Wuhan 430030, China; ${ }^{3}$ The Institute of Brain Research, Huazhong University of Science and Technology, Wuhan 430030, China and ${ }^{4}$ Department of Biology, Boston University, Boston, MA 02215, USA

*Corresponding author: Y Lu or L-Q Zhu or J-Z Wang, Department of Pathophysiology, Huazhong University of Science and Technology, \#13 Hangkong Road, Wuhan 430030, China. Tel: +86 27 83692625; Fax: +86 27 83692608; E-mail: lym @ mail.hust.edu.cn or zhulq@ @mail.hust.edu.cn or wangjz@mails.tjmu.edu.cn

Abbreviations: MT1, melatonin receptor 1; MT2, melatonin receptor 2; GPCR, G protein-coupled receptor; CNS, central nervous system; LTP, long-term potentiation; GABA, $\gamma$-aminobutyric acid; FRET, fluorescence resonance energy transfer; MEL, melatonin; mEPSCs, miniature excitatory postsynaptic currents; GSK-3 $\beta$, glycogen synthase kinase-3 $\beta$; CRMP-2, collapsin response mediator protein-2; aPKC, atypical protein kinase C; GIPs, GPCR-interacting proteins

Received 29.3.14; revised 26.10.14; accepted 30.10.14; Edited by L Greene; published online 12.12 .14
} 
( $\sim 12$ to $24 \mathrm{~h}$ ); polarization occurs at stage 3 ( 24 to $48 \mathrm{~h})$, in which a single neurite initiates a rapid elongation to become the axon while others acquire dendritic identity; stage 4 ( $3-$ 4 days) is characterized by rapid outgrowth of axon and dendrites; and at stage 5 (7 days onwards), the maturation of axon and dendrites is essential for functional synapse formation. ${ }^{20,21}$ In the present study, we have identified a novel role for the MT2 receptor in functional axonogenesis and show that activation of the MT2 receptor is crucial for functional axonogenesis and synaptic transmission in central neurons. Using fluorescence resonance energy transfer (FRET) imaging combined with peptide blocking assays, we have identified Akt as an interacting partner and a substrate of the MT2 receptor. Activation of the MT2 receptor-Akt signaling cascade promotes the formation of functional synapses in the hippocampus, whereas inhibition of the MT2 receptor arrests axonogenesis and synaptic transmission. Given the implications of the MT2 receptor in learning and memory, we propose that targeting MT2 receptor-Akt signaling may be a feasible strategy for stimulating functional synaptic circuit assembly.

\section{Results}

Accumulation of the MT2 receptor in polarized axons. To explore the role of MT1 and MT2 receptors in axon development, we first measured their cellular localization in dissociated rat hippocampal neurons by co-immunostaining for the MT1 receptor or MT2 receptor and Tuj1, a neuronspecific class III $\beta$-tubulin. ${ }^{22}$ We found that the MT2 receptor was uniformly distributed on all neurites with tip enrichment in stage 2 neurons, while strong fluorescence signal was only detected at the polarized axon tip but not in the dendrites in stage 3 neurons (Figure 1a). Quantitative analysis showed that the MT2 receptor was differentially enriched at the neurite tips in stage 2 neurons, whereas more exclusive axon tip enrichment of the MT2 receptor was observed in stage 3 neurons (Figures $1 \mathrm{~b}$ and e). The MT1 receptor had a similar distribution to the MT2 receptor at stage 2, but no polarized distribution of the MT1 receptor was detected at stage 3 (Figures 1c-e). The specificity of the MT2 receptor antibody was verified by the peptide blocking experiment (Supplementary Figure 1). These results suggest that the MT2 receptor might have a potential role in axon differentiation, an early stage of synapse development. ${ }^{1}$

The MT2 receptor is essential for axon development. To determine the role of the MT2 receptor in axon differentiation, we first applied an in vivo study by in utero electroporation with MT2-specific shRNA (Supplementary Figure 2a and b), we found that neuronal migration (P0) and axon outgrowth (P3) were significantly retarded by MT2 knockdown (Figure 2a, boxes 1 and 2). The SMI312 (a specific axonal marker previously used in an in vivo study ${ }^{23}$ ) immunoreaction was almost diminished in $\mathrm{MT}^{-/-}$mice, whereas strong SMI312 immunoreactivity was detected in the $I Z$ region with enriched axon bundles in $\mathrm{C} 3 \mathrm{H}$ mice (Figure $2 \mathrm{~b}$, boxes 1-4). Recent studies have revealed that many cortical neurons initiate axon outgrowth during radial migration, before they reach the $\mathrm{CP}^{24,25}$ Our data strongly suggests that downregulation of MT2 signals in vivo arrests early axonal development.

We then used high affinity MT2 receptor selective antagonists, 4P-PDOT or K185 and MT2 shRNA for in vitro studies. In rat hippocampal neuron cultures, inhibition of the MT2 receptor by 4P-PDOT or K185 significantly inhibited formation and outgrowth of the axon: $\sim 41.7 \%$ of the neurons had no axon and only $\sim 3.7 \%$ of them grew multiple axons after $4 \mathrm{P}$ PDOT treatment, and $\sim 42.5 \%$ of the neurons had no axon and $\sim 3.5 \%$ neuron developed multiple axons after K185 treatment (Figures 2c and d); 4P-PDOT and K185 treatment also reduced axon length with an increased dendrite length and unchanged total neurite number (Figures $2 \mathrm{e}-\mathrm{g}$ ). With in vitro specific shRNA targeting (Supplementary Figure 2a and b), we found that knockdown of the MT2 receptor, but not the MT1 receptor, decreased axon formation and outgrowth with an increase in dendrite length, and the deficits of axon development were not rescued by IIK7, a specific MT2 receptor agonist (Figures $2 \mathrm{~h}-\mathrm{l}$ ). These data demonstrate that suppression of the MT2 receptor arrests axonogenesis, indicating an essential role for MT2 receptor in axon development.

MT2 receptor activation promotes axon outgrowth. We next investigated whether activation of the MT2 receptor promotes axon outgrowth and axon-dendrite differentiation by incubation of rat hippocampal neuron cultures with MT2 agonists, melatonin (MEL) or IIK7 (the concentration of IIK7 was chosen according to a dose-dependent experiment, see Supplementary Figure 3). In the DMSO control group, $\sim 81.5 \%$ neurons developed a single-axon with $8.9 \%$ multiple-axon and 9.6\% no-axon neurons (Figures $3 a$ and b). Stimulation of the MT2 receptor by MEL or IIK7 increased the length of single axon projections without affecting dendrite length and neurite number, and $\sim 40.6$ or $41.2 \%$ of MEL-treated or IIK7-treated neurons developed multiple axons (Figures 3a-e), indicating the sufficiency of MT2 receptor activation in axon differentiation. The effect of MT2 receptor stimulation is unique since only blockage of the MT2 but not MT1 receptor compromised the IIK7 facilitation of the formation and outgrowth of multiple axons (Figures $3 f-j)$. Furthermore, only overexpression of the rat MT2 receptor but not MT1 receptor increased axon formation and outgrowth (Figures $3 \mathrm{k}-0$ ), consistent with the specific effect of MT2 in axon development.

Neurons generally do not develop a new axon after $72 \mathrm{~h}$ in culture, a time point defined as the maintenance phase of polarity. ${ }^{20}$ To explore whether activation of the MT2 receptor still promotes axon formation in the maintenance phase of neuronal development in cultured rat neurons, we expressed DsRED $36 \mathrm{~h}$ after plating to allow imaging of axon outgrowth. We treated neurons with IIK7 or DMSO at $72 \mathrm{~h}$ and examined axon-neurite development $72 \mathrm{~h}$ later (144h in total) (Supplementary Figure $4 \mathrm{a}-\mathrm{c}$ ). Most neurons developed a single-axon with $10.4 \%$ multiple-axon neurons in controls, whereas 42.4 or $43.6 \%$ neurons treated with MEL or IIK7 developed multiple long axons, as labeled by Tau1 (Supplementary Figure $4 \mathrm{a}-\mathrm{c}$, boxes 1 and 2), indicating that activation of the MT2 receptor in developed neurons is sufficient to initiate new axon formation. 

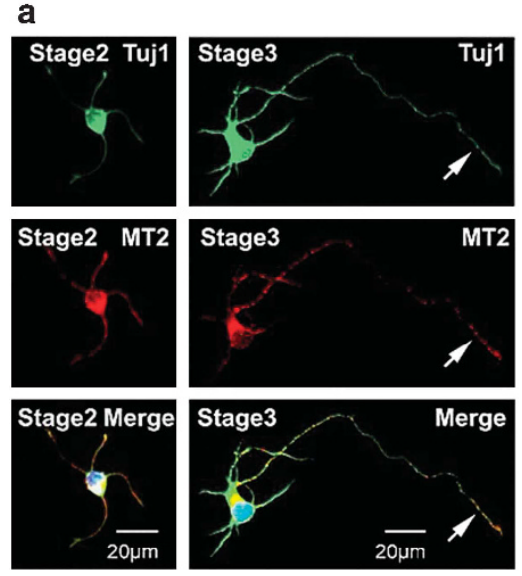

C
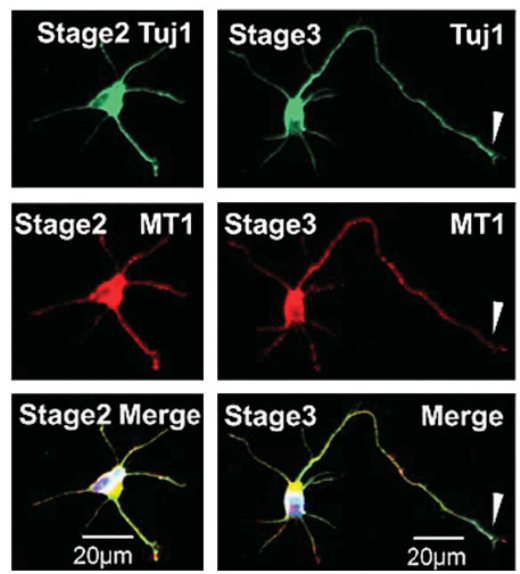

b

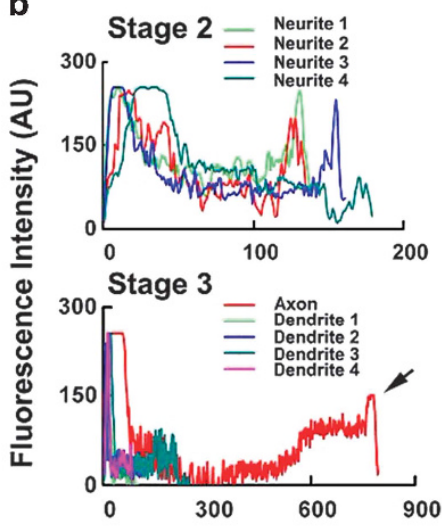

Distance from cell body (pixel)

d

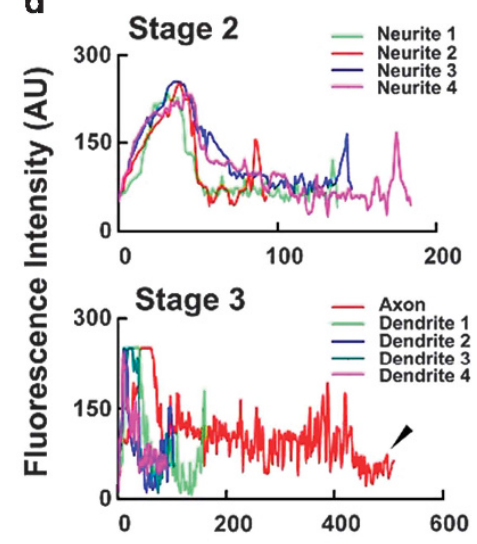

e

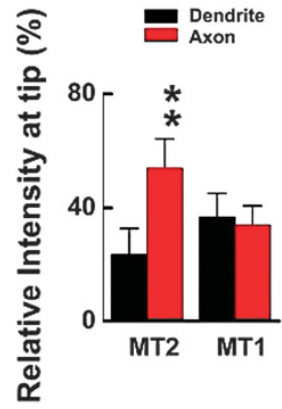

Distance from cell body (pixel)

Figure 1 MT2 accumulation in the polarized axon terminals. (a-d) Distribution of MT2 and MT1 in stage $2(12 \mathrm{~h})$ and stage $3(48 \mathrm{~h})$ cultured rat hippocampal neurons. The neurons were co-stained with anti-MT2 (a) or anti-MT1 (c) (red) and anti-Tuj1 (green) antibodies, and profiles of MT2 (b) and MT1 (d) immunofluorescence intensity in different segments of the neuronal processes during stage 2 and stage 3. Arrow and arrowhead indicate, respectively, axon tip distribution of MT2 and MT1 in stage 3 neurons; AU means arbitrary unit. (e) Relative immunofluorescence intensity of MT2 and MT1 at the axon and dendrite tips of stage 3 neurons normalized to that of the cell body. Data are mean \pm S.E.M., $n=11,{ }^{\star \star} P<0.01$ versus dendrite

To explore whether activation of the MT2 receptor can convert the short processes to longer processes with axonal morphology in the maintenance phase of neuron development, we used time-lapse imaging and observed that the neurons generally developed one long axon (arrowhead) with some shorter neurites (arrows) at $72 \mathrm{~h}$ after plating (Figures $4 \mathrm{a}$ and $\mathrm{c}$, box 1), and some of the short neurites grew into long axons at $144 \mathrm{~h}$, as labeled by Tau1, after treatment with IIK7or MEL (Figure 4b, boxes 1-3; Figure 4d, boxes 2 and 3 ).

These data provide compelling evidence that stimulation of the MT2 receptor promotes axon outgrowth not only during the establishment phase, but also during the maintenance phase of neuronal development.

MT2 receptor activation potentiates functional synaptic transmission. Functional axons possess the ability of presynaptic neurotransmitter release and therefore initiate postsynaptic responses. ${ }^{26}$ To explore whether the palingenetic multiple axons induced by MT2 receptor activation were able to form functional synapses, we first examined the uptake and release of FM4-64 dye, which is widely used for examining the function of presynaptic axon terminals. ${ }^{27} \mathrm{We}$ treated rat primary hippocampal neurons at 3 div with IIK7, and measured FM4-64 uptake and release at the axons with time-lapse imaging 5 days after the treatment (8 div). Neurons with multiple axons were visualized by EGFP (Figure 5a). Upon an initial stimulation with $45 \mathrm{mM} \mathrm{K}^{+}$for $1 \mathrm{~min}$, the axons and the branches were positively loaded with FM4-64 (Figure 5a, boxes 1-3, R-pre), suggesting normal uptake in the axons. The FM4-64 was almost completely depleted when the same neuron was further treated with $90 \mathrm{mM} \mathrm{K}^{+}$(Figure 5a, boxes 1-3, R-post, and $\mathrm{R}$-sub). By quantitative analysis, we did not observe any significant change in time constant of FM4-64 release (Figure 5b). These data suggest that the multiple axons induced by MT2 receptor activation are capable of releasing synaptic vesicles, reflecting a maturation of the presynaptic release machinery. ${ }^{28}$ To determine the postsynaptic response, we performed whole-cell patch clamp recordings of the miniature excitatory postsynaptic currents (mEPSCs). We found that activation of the MT2 receptor by IIK7 dramatically increased the frequency of spontaneous mEPSCs while co-administration with 4P-PDOT completely retained the enhancement from IIK7 (Figures $5 c$ and d), 

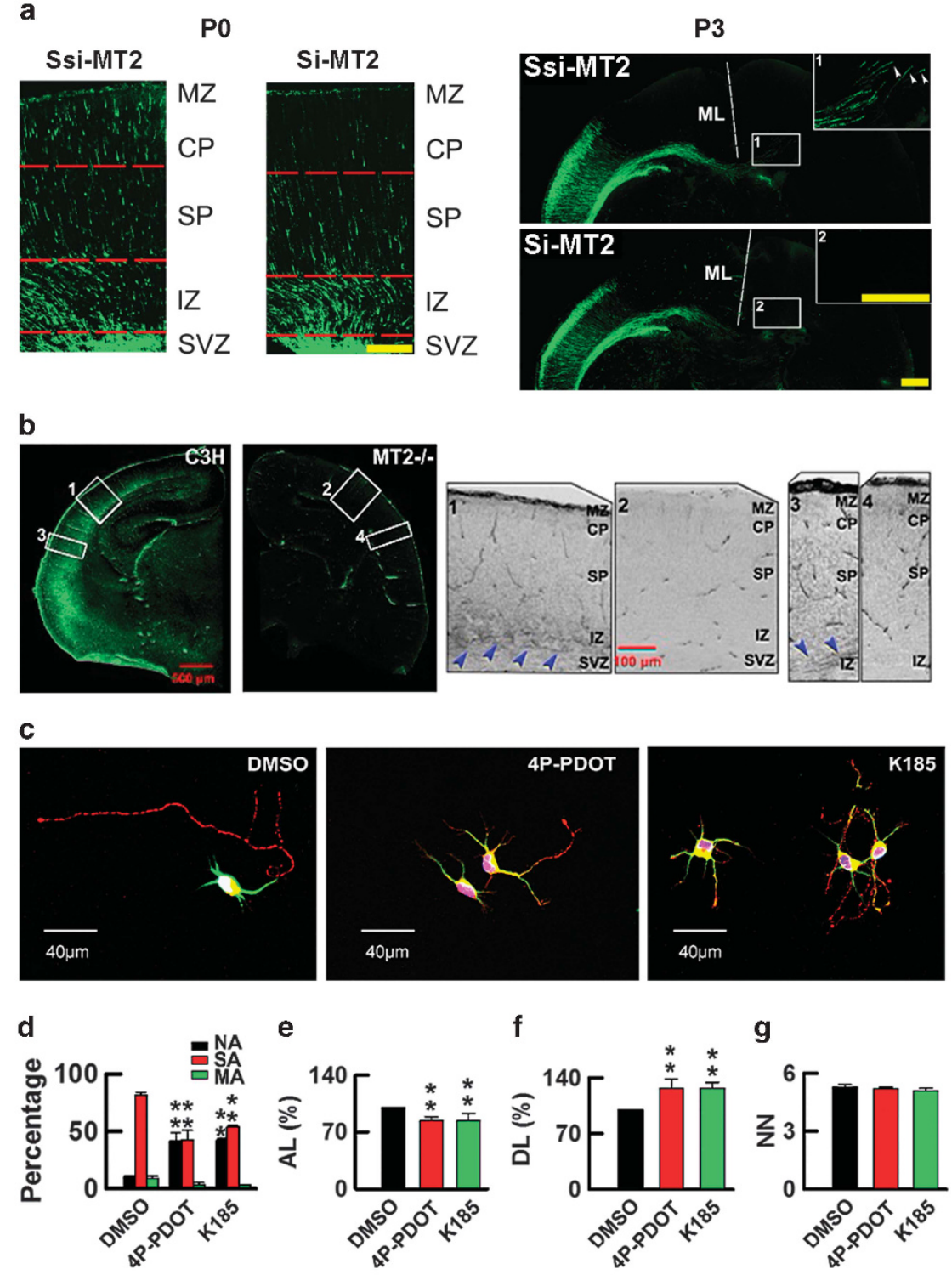

g

h
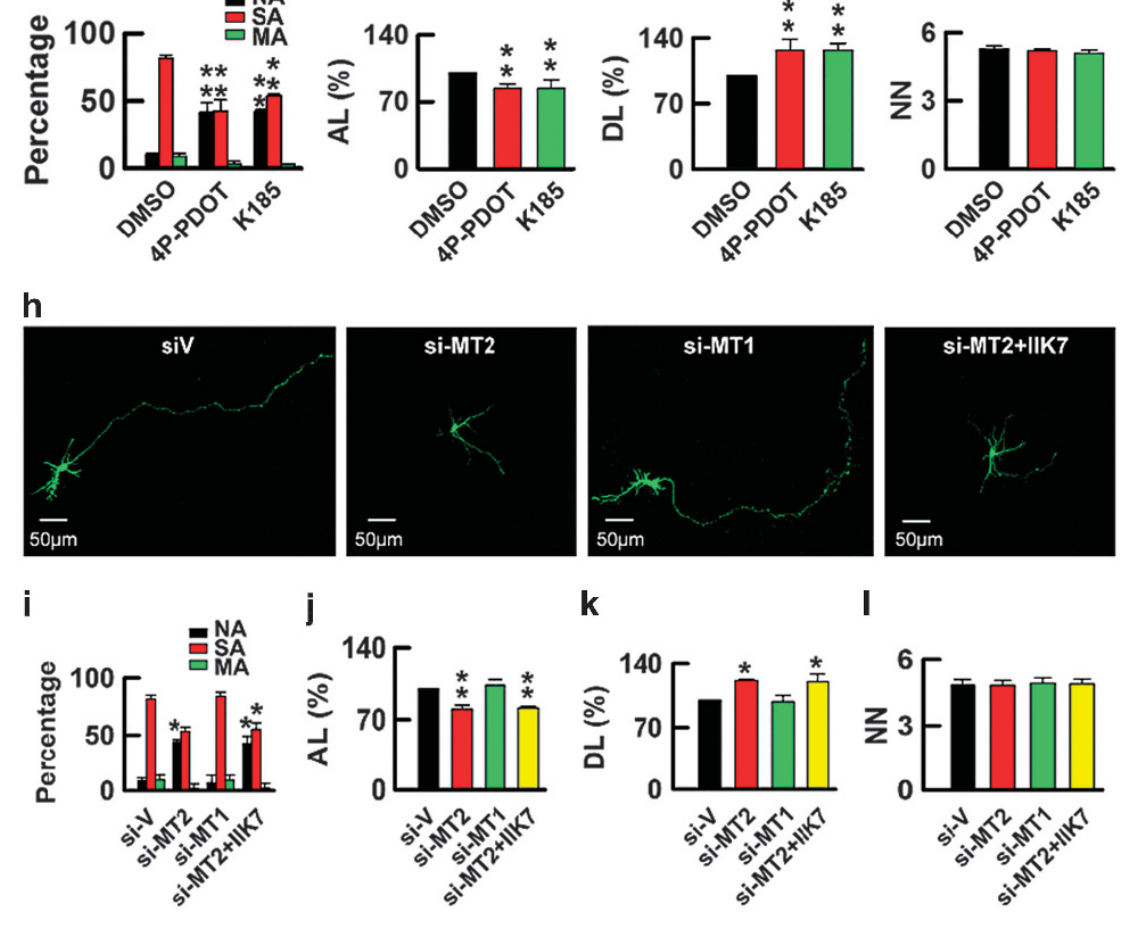

$50 \mu \mathrm{m}$ 
suggesting potentiated synaptic transmission by MT2 receptor activation. Meanwhile, the amplitude and the rise/decay time of mEPSCs were not altered upon all treatments (Figures $5 e$ and $f$ ), indicating that the increased mEPSCs frequency induced by MT2 receptor activation may have resulted from an increased number of synapses formed by multiple functional axons but not from an increase in neurotransmitter release from the axon terminals.

MT2 receptor activates the Akt/GSK-3 $\beta /$ CRMP-2 cascade. Specific signal transduction pathways mediate the biological effects of membranous receptors. To clarify the related signaling components downstream of the MT2 receptor, we first examined the glycogen synthase kinase-3 $\beta$ (GSK-3 $\beta$ ) and collapsin response mediator protein-2 (CRMP-2), which are widely recognized mediators for specifying axon/dendrite fate and synaptic activity. ${ }^{29-31}$ In rat hippocampal neuron cultures, we found that activation of the MT2 receptor by MEL or IIK7 led to inactivation of GSK-3 $\beta$ and this inactivation was associated with an increased level of dephosphorylated CRMP-2 at Thr514 (pT514-CRMP2, an inactive form of CRMP-2; Figures $6 a$ and c). Conversely, inhibition of the MT2 receptor by K185 stimulated GSK-3 $\beta$ and inactivated CRMP-2 (Figures $6 a$ and $c$ ). Together with the observations in HEK293 cells with transient expression of human MT2 receptor and IIK7 treatment (Figures $6 \mathrm{~b}$ and $\mathrm{d}$ ), we conclude that upregulation of the MT2 receptor activates CRMP-2 via downregulation of GSK-3 $\beta$.

Since Akt is the most recognized upstream regulator of GSK-3 $\beta,{ }^{32}$ we studied whether Akt links the MT2 receptor to GSK-3 $\beta$ and the CRMP-2 pathway. We found that phosphorylation of Akt at serine473 (pS473-Akt, an activated form of Akt) increased when MT2 was activated by MEL or IIK7, whereas the level of pS473-Akt decreased by inhibiting MT2 with K185 (Figures 6a and c). Comparable results were also observed in HEK293 cells with transient expression of the human MT2 receptor and IIK7 treatment (Figures 6b and d). Furthermore, treatment of cultured neurons or HEK293 cells with a specific Akt inhibitor (TCN) counteracted the effects of MT2 receptor activation-induced GSK-3 $\beta / C R M P-2$ signaling (Figures 6a-d). Concomitantly, TCN inhibited not only IIK7induced multiple axon formation, but also normal axon differentiation (Figures $6 \mathrm{e}$ and $\mathrm{f}$ ). In neurons cultured from $\mathrm{MT2}^{-1-}$ mice, administration of IIK7 could not activate Akt or rescue the TCN-induced Akt inhibition (Figures $6 \mathrm{~g}$ and $\mathrm{h}$ ). These results suggest that MT2 receptor activation promotes functional synaptogenesis through the Akt/GSK-3//CRMP-2 pathway. In addition, we found that the activity of atypical PKC (aPKC) was not changed by manipulation of MT2 and PKC $\zeta$ pseudo, a specific aPKC inhibitor, which did not affect the axon potentiation of IIK7 (Supplementary Figure 5a-c).

MT2 receptor functionally interacts with Akt. To explore a potential interaction between the MT2 receptor and Akt, we performed co-immunoprecipitation. We observed that the Akt protein was precipitated by the anti-MT2 antibody, and the MT2 receptor was present in the Akt complex in E18 rat hippocampus (Figures $7 a$ and $b$ ). To define whether this association was due to a direct protein-protein interaction between MT2 receptor and Akt, we co-transfected DsREDMT2 and GFP-AktPH (pleckstrin homology) and used FRET to measure the interaction of Akt and the MT2 receptor. By bleaching the RFP at $543 \mathrm{~nm}$, we found that the FRET appeared most apparently in the membranous region of the cells with overexpression of MT2, and the FRET effect almost vanished when the $\mathrm{PH}$ domain of Akt was mutated (GFP-AktPH ${ }^{\mathrm{R} 25 \mathrm{C}}$ ) (Figure 7c), suggesting that Akt binds to MT2 receptor directly. Parallel co-immunoprecipitation and FRET experiments were performed for the MT1 receptor and we did not find any interaction between the MT1 receptor and Akt (Supplementary Figure 6), ruling out the possible involvement of the MT1 receptor in Akt activation.

To identify the binding motif of Akt in the MT2 receptor, we generated a series of MT2 peptides and found that a peptide fragment consisting of amino acids 341-352 (HLTEDLQGPVPP, MT2 ${ }_{\mathrm{CT}}$ ) was capable of blocking the MT2 receptor-Akt association (Figures $7 \mathrm{~d}$ and $\mathrm{e}$ ) and activation of Akt (Figures $7 f$ and $g$ ). To examine whether disrupting the MT2 receptor-Akt interaction influenced MT2 receptor-mediated axon-dendrite differentiation, we generated membrane permeable $M T 2_{\mathrm{CT}}$ peptides by fusing the MT2 $2_{\mathrm{CT}}$ to the cellmembrane transduction domain of the HIV-1 Tat protein (Tat$\mathrm{MT2}_{\mathrm{CT}}$ ). By using Tau1/MAP2 double-immunofluorescence labeling, we found that administration of Tat-MT2 ${ }_{\mathrm{CT}}(\mathrm{P}-3)$ not only reduced the number of Tau1-positive neurites, but also suppressed multiple axon formation induced by IIK7 (Figure 7h). Quantitative data showed that $\sim 35.5 \%$ of the neurons grew multiple axons and only less than $3.6 \%$ of the neurons did not grow an axon when IIK7 was administered; whereas only $\sim 3.8$ or $\sim 4.4 \%$ of the neurons grew multiple axons when Tat-MT2 ${ }_{\mathrm{CT}}$ was added in the presence or absence of IIK7 (Figure 7i). Application of Tat-MT2 ${ }_{\mathrm{CT}}$ also reduced axon length with an increase in dendrite length (Figures 7j-I). To further explore whether disrupting the MT2 receptor-Akt interaction affects synaptic transmission, we performed whole cell patch clamp to record the mEPSCs. We found that Tat-MT2 $2_{\mathrm{CT}}$ treatment suppressed the IIK7-augmented mEPSC frequency (Figures $7 \mathrm{~m}-0$ ).

Figure 2 MT2 receptor is essential for axon development. (a) Rats embryos were electroporated with mU6-MT2-shRNA-pUbi-EGFP (si-MT2) or scrambled one (Ssi-MT2) at E16 and the slices were prepared at postnatal day 0 (P0) or day 3 (P3). MZ, marginal zone; CP, corticalplate; SP, subplate; IZ, intermediate zone; SVZ, subventricular zone; ML, midline. Bar $=200 \mu \mathrm{m}$ for P0, $500 \mu \mathrm{m}$ for P3. Arrowheads indicate the axonal terminals. (b) Coronary slices from C3H and MT2 $-/$ - mice at P0 were stained by SMI312, and high magnifications were from boxes 1 to $4(n=4)$. (c) Primary neuronal cultures from E18 rat hippocampuswere treated with MT2 receptor antagonists, 4P-PDOT (10 $\mu$ M) or $\mathrm{K} 185(10 \mu \mathrm{M})$, or vehicle control DMSO at $4 \mathrm{~h}$ after plating. Seventy-two hours after plating, the cultures were co-stained with Tau1 (red) and MAP2 (green) ( $n=87-115)$. (d-g) Bar graphs show the percentage of no-axon (NA), single-axon (SA), and multiple-axon (MA) neurons, as well as axon length (AL), dendrite length (DL), and the neurite number (NN).Data are mean \pm S.E.M. ${ }^{* *} P<0.01$ versus DMSO. (h) Primary neurons from E18 rat hippocampus were transfected with shRNA of MT2 (si-MT2) or MT1 (si-MT1) or the vector plasmid (siV) before plating. IIK7 $(10 \mu \mathrm{M})$ was added at $4 \mathrm{~h}$ after plating. Images were captured at $72 \mathrm{~h}$ after plating $(n=42-45)$. (i-I) Bar graphs show the percentage of no-axon (NA), single-axon (SA), and multiple-axon (MA) neurons, as well as axon length (AL), dendrite length (DL), and the neurite number (NN). ${ }^{*} P<0.05$, ${ }^{* *} P<0.01, v e r s u s$ siV 
a
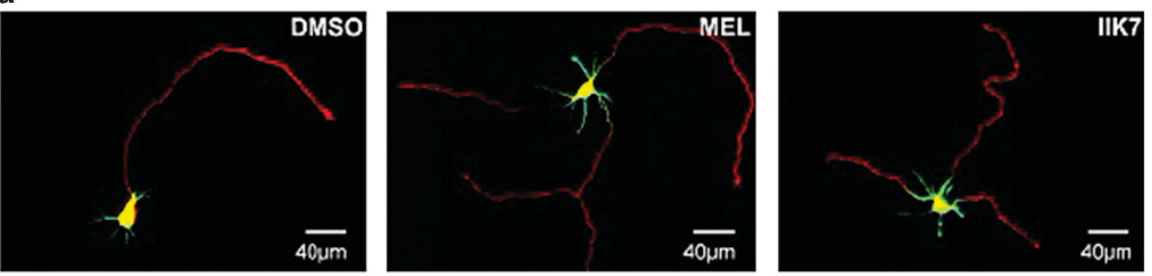

b

c

d

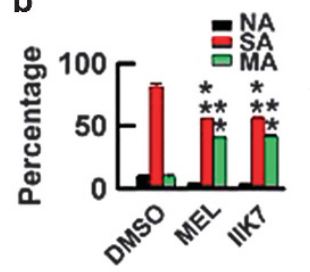

140
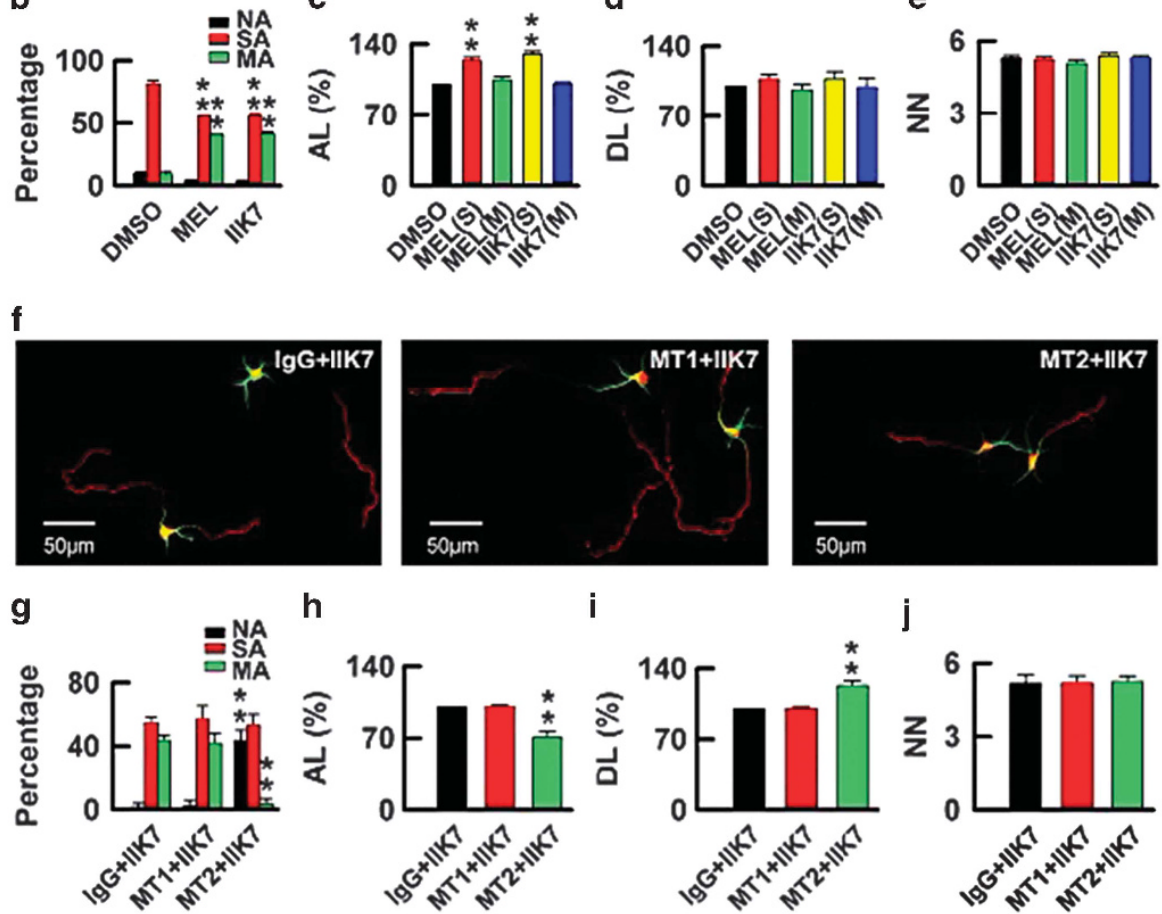

h

i

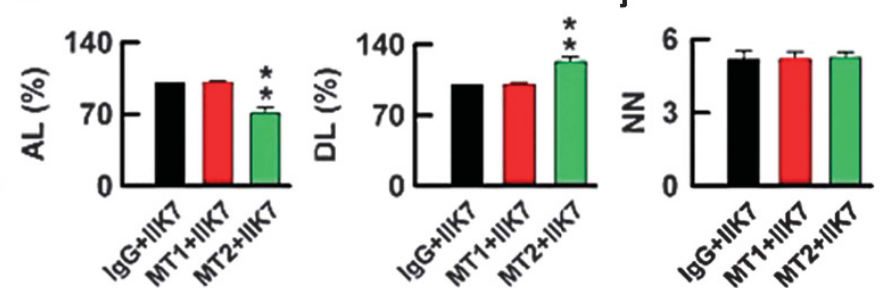

k
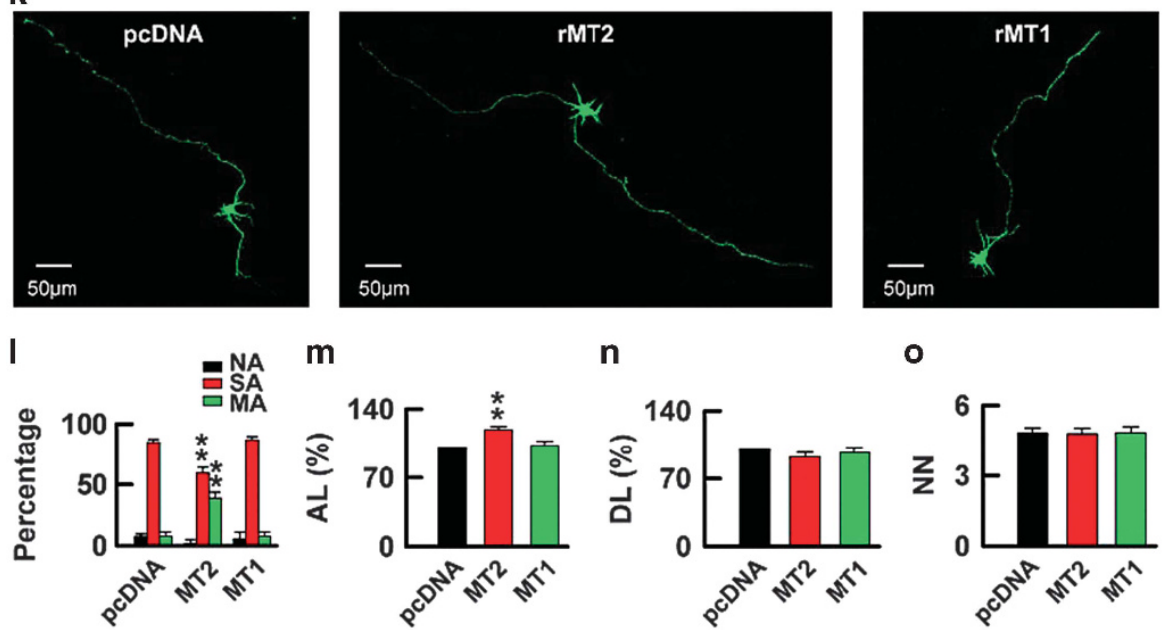

m

n

○
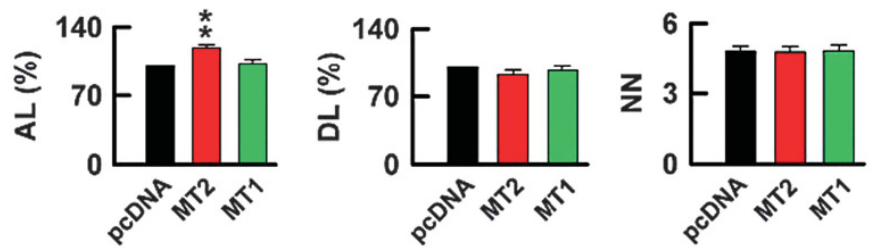

Figure 3 Activation of MT2 receptor promotes functional axon formation. (a) Dissociated rat hippocampal neurons (E18) were treated with MT2 receptor agonists, MEL or IIK7, or DMSO at 4 hrs after plating. 72 hrs after the treatment the cultures were co-stained with Tau- 1 (red) and MAP2 (green) $(n=69-115)$. (b-e) Bar graphs show the percentages for different types of neurons in different treatments, NA means neurons with no axon, SA means neurons with singleaxon, and MA means neuron with multiple axons, as well as axon length (AL), dendrite length (DL), and the neurite number (NN). Data are mean \pm S.E.M. ${ }^{*} P<0.01$, versus DMSO. (f) Dissociated rat hippocampal neurons (E18) were treated with IIK7 plus antibodies against the MT1 receptor (Cat No. sc-13179, Santa Cruz Biotech.; $n=46$ cells) or the MT2 receptor (Cat No. sc-28456, Santa Cruz Biotech.; $n=53$ cells) or control non-specific lgG ( $n=55$ cells) at $4 \mathrm{~h}$ after plating. Seventy-two hours after plating, the cultures were co-stained with Tau1 (red) and MAP2 (green). ( $(\mathbf{g}-\mathbf{j})$ Bar graphs show the percentages of no-axon (NA), single-axon (SA), and multiple-axon (MA) neurons, and the axon length (AL), the dendrite length (DL), and the neurite number (NN). Data are mean \pm S.E.M., ${ }^{* *} P<0.01$ versus IgG+llK7. (k) Rat cultured neurons were transfected with rat MT2 (rMT2) or MT1 (rMT1) or vector (pcDNA) before plating and the images were captured at $72 \mathrm{~h}$ after plating $(n=53-54)$. (I-0) Bar graphs show the percentages of no-axon (NA), single-axon (SA), and multipleaxon (MA) neurons, and the axon length (AL), the dendrite length (DL), and the neurite number (NN). Data are mean \pm S.E.M., ${ }^{* *} P<0.01$ versus pcDNA 
Together, these data demonstrate that a direct interaction of the MT2 receptor with Akt stimulates axonogenesis, and thereby promotes synaptic transmission.

\section{Discussion}

The MT2 receptor is expressed throughout the brain, including hippocampus, prefrontal cortex, suprachiasmaticnuclei, and cerebellar cortex. ${ }^{7}$ Loss of the MT2 receptor and decreased levels of melatonin have been reported in brains of anxiety disorders and Alzheimer's disease, while an impairment of learning and memory has also been observed in MT2 receptor knockout mice, ${ }^{12}$ it is therefore conceivable that the MT2 receptor must have a role in preserving cognitive function. Since axon development and synapse formation have a critical role in learning and memory, we investigated the roles of the MT2 receptor in axonogenesis and synaptic transmission. We have demonstrated that (i) activation of the MT2 receptor promotes functional axonogenesis with an enhanced synaptic transmission in hippocampal neurons, whereas inhibition of the MT2 receptor arrests axon differentiation; (ii) the signaling components downstream of the MT2 receptor involve activation of the Akt/GSK-3 $\beta / C R M P-2$ cascade; (iii) the MT2 receptor directly binds to Akt; and (iv) disruption of MT2Akt binding by application of an MT2 receptor intracellular tail fragment abolishes MT2-stimulated axonogenesis and synaptic transmission. Taken together, our findings support a working model as illustrated in Figure 8 that the MT2 receptor directly couples with Akt to stimulate functional axonogenesis and synaptic transmission through inhibiting GSK-3 $\beta$, thus decreasing the phosphorylation of CRMP-2.

In response to melatonin, the MT2 receptor is capable of parallel or alternate signaling cascades by modulating different $\mathrm{Ga}$ subforms and the $\mathrm{G} \beta \gamma$ complex. ${ }^{7}$ The MT2 receptor can form homodimers or heterodimers in response to different stimulations or by interacting with other proteins in the plasma membrane. ${ }^{7}$ Activation of the MT2 receptor frequently activates the PI3K/Akt pathway and thus inhibits GSK-3 $\beta$, the latter is a critical step in the formation of neuronal polarity. ${ }^{33}$ Therefore, we measured the activity of Akt and GSK-3 $\beta$ and found that activation of Akt was closely correlated with GSK-3 $\beta$ inhibition when the MT2 receptor was activated; meanwhile, the inhibitory phosphorylation of CRMP-2 was suppressed. These data reveal that activation of the MT2 receptor stimulates functional axonogenesis and synaptic transmission through the Akt/GSK-3 $\beta / C R M P-2$ pathway. Previous studies have demonstrated that CRMP-2 is a major substrate of GSK-3 $\beta$ and inhibition of GSK-3 $\beta$ can lead to a decreased phosphorylation (activation) of CRMP-2, which represents a proverbial signaling pathway directing axonogenesis. $^{30,34}$

GSK-3 $\beta$ is also regulated by atypical protein kinase C (aPKC) and activation of aPKC stimulates axon development. ${ }^{35}$ However, it was not known whether aPKC is regulated by GPCR/MT2. In the current study, we did not observe any noticeable change in aPKC during manipulation of the MT2 receptor; furthermore, inhibition of aPKC did not attenuate the facilitative effect of IIK7 on axon differentiation. These data may rule out the role of aPKC in MT2 receptor activation-induced axonogenesis and synaptic transmission.
To understand how the MT2 receptor initiates the Akt/ GSK-3 $\beta /$ CRMP-2 pathway, we did co-immunoprecipitation and found that the MT2 receptor was bound to Akt. We then performed FRET experiments and confirmed the direct interaction of the MT2 receptor with Akt. To further verify the association site and the effects, we used a peptide complementary to the C-terminal of the MT2 receptor. We found that application of the peptide abolished the binding of the MT2 receptor with Akt, and simultaneously blocked the MT2mediated axonogenesis and synaptic transmission. These results suggest that the binding site of the MT2 receptor to Akt may locate at its $\mathrm{C}$-terminal, the most important region in a GPCR for interaction with GPCR-interacting proteins (GIPs), and a region of posttranslational modification and coupling with $\mathrm{G}$ proteins. ${ }^{36} \mathrm{MT} 2$ receptor activation also changed the ratio of $\mathrm{CAMP} / \mathrm{cGMP}^{37}$ of which the local and long-range reciprocal regulation in axon-dendrite differentiation have been reported recently. ${ }^{38}$ We also demonstrated that the $\mathrm{PH}$ domain of Akt is essential for the interaction with the MT2 receptor at the $\mathrm{C}$-terminal. Previous studies had revealed that Akt could form a complex with the dopamine D2 receptor, $\beta$ arrestin and phosphatase $2 \mathrm{~A}$, but the exact interacting domain is not clear. ${ }^{39}$ To date, this is the first report showing direct binding of a membrane receptor with Akt at its $\mathrm{PH}$ domain, which is known to bind with multiple intracellular signal proteins including Tcl1, JIP1, Grb10 and RasGAP. ${ }^{40}$

Generation of functional axons is essential for communication between nerve cells in the brain. Deficits in axon guidance and synaptic disorders that disrupt the normal function of the neuronal network have been observed in Alzheimer's disease. ${ }^{41}$ Preserving functional axons may therefore be helpful to prevent or rescue the progressive decline of neuronal function in this disease. Currently, regenerating damaged axons or facilitating outgrowth of damaged axons is the main approach to promote recovery of connectivity in many neural disorders. ${ }^{42,43}$ Our study here, along with the previous reports, provides a possible novel strategy to generate new axons on polarity-established neurons, which might help generate new axons to promote functional recovery in patients with neural injuries. ${ }^{33,44}$ Both loss of the MT2 receptor and a decrease in melatonin are highly correlated with Alzheimer's disease, ${ }^{12,14,15}$ and the cellular protection of melatonin or MT2 receptor activation has been well clarified. ${ }^{45,46}$ Moreover, dopamine, ${ }^{47}$ estrogen, ${ }^{48}$ thyroid hormone, ${ }^{49}$ acetylcholine ${ }^{50}$ glutamate, ${ }^{51}$ GABA, $^{52}$ or their receptors ${ }^{53}$ can affect or crosstalk with the melatonin/MT2 receptor, and most of these molecules have an important role in axonogenesis or synapse formation. ${ }^{54-57}$ It remains unclear whether and how melatonin/MT2 receptor signaling interacts with these hormone and neurotransmitter systems in the brain, but it is conceivable that activation of the MT2 receptor could be a practical strategy to regenerate renascent axons from dendrites on mature neurons for the treatment of neurological diseases such as AD.

\section{Materials and Methods}

Reagents, antibodies, constructs, and mice. IIK7, K185, melatonin (MEL), and 4P-PDOT (Sigma, St Louis, MO, USA), TCN (Merck, Darmstadt, Germany), and PKC- $\zeta$ pseudosubstrate (Biosource, Camarillo, CA, USA) were dissolved in DMSO. The following antibodies were used: goat anti-MT2, goat anti-MT1 (Santa Cruz, Carlsbad, CA, USA), mouse anti-neurofilament 165 
a
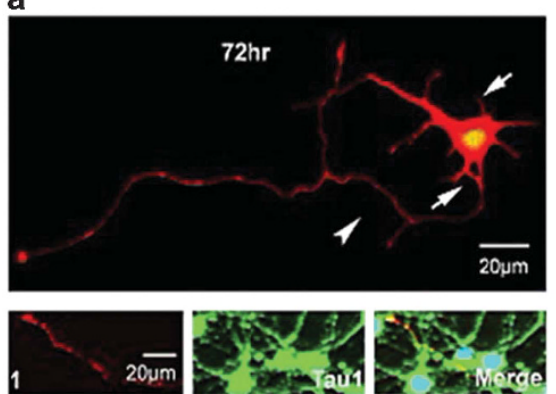

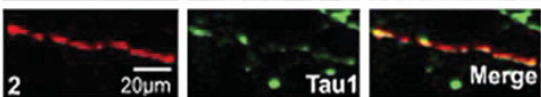

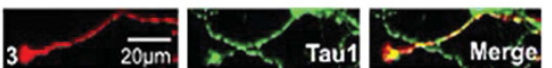

c
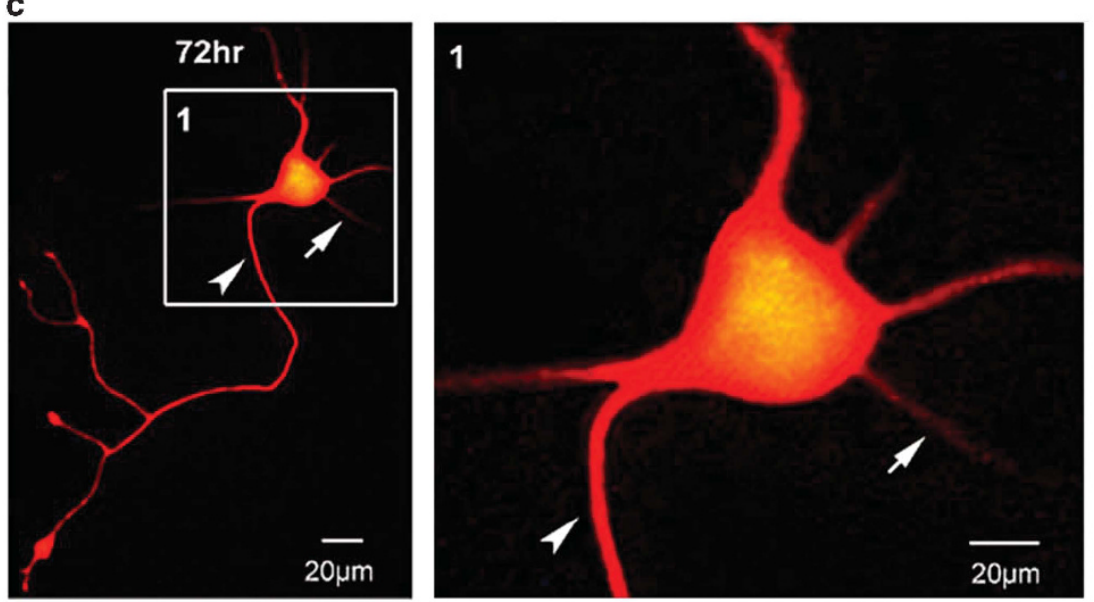

d

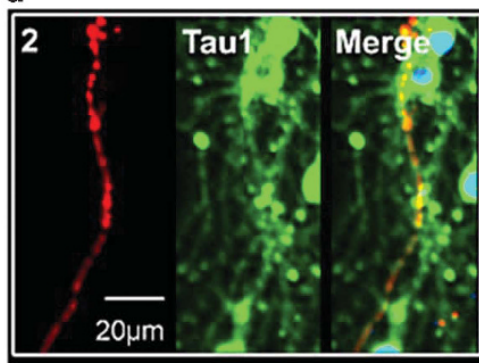

MEL

$144 \mathrm{hr}$
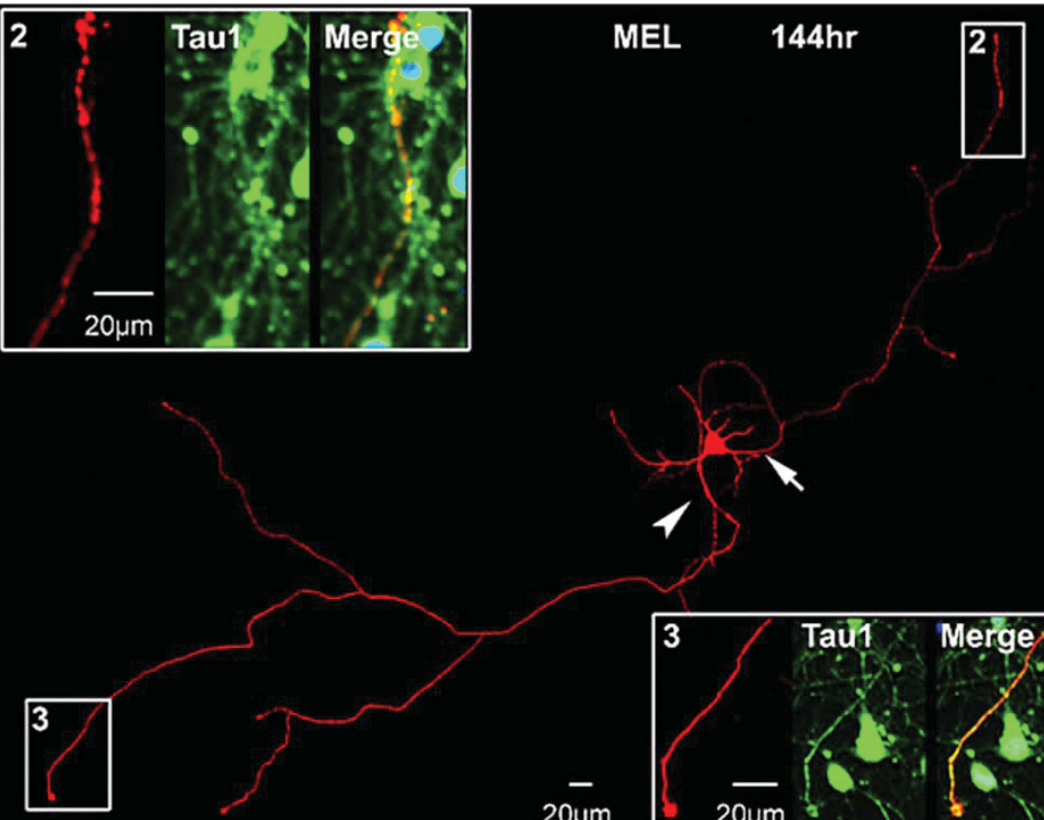

b

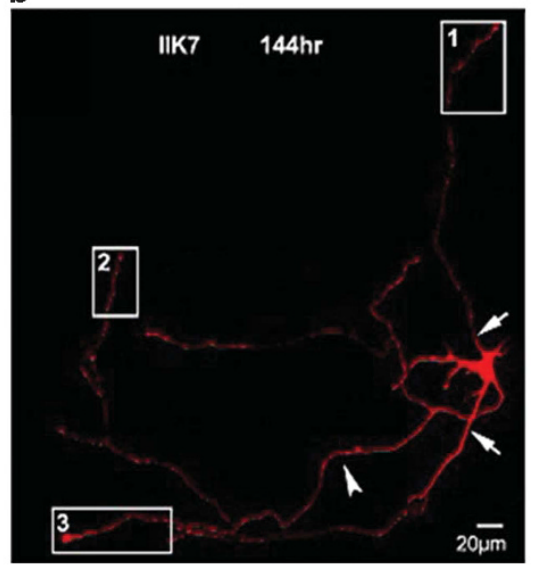

$0 \mu m$

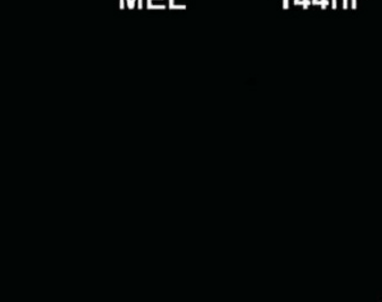

$20 \mu \mathrm{m}$

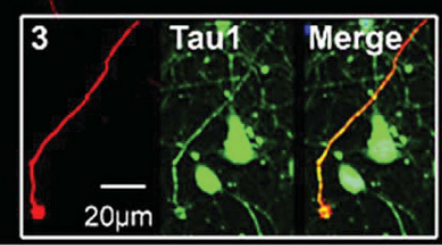


(2H3, Developmental Studies Hybridoma Bank), mouse anti-SMl312 (Covance, axonal marker, Austin, TX, USA), mouse anti-Tau1 (Chemicon, axonal marker Millipore, Billerica, MA, USA), mouse anti-Tuj1 (Covance, neurites marker), rabbit antiMAP2 (Chemicon, dendritic marker), rabbit anti-Akt, rabbit anti-phospho-Akt (Ser473), rabbit anti-GSK-3 $\beta$, rabbit anti-phospho-GSK-3 $\beta$ (Ser9), rabbit anti-PKC $\zeta$, rabbit antiphospho-PKC $\zeta / \lambda$ (Thr 410/403) and rabbit anti-phospho-CRMP-2 (Thr514) (Cell
Signaling, Beverly, MA, USA); mouse anti-CRMP-2 (Immuno-Biological Laboratories, Minneapolis, MN, USA) and the DNA labeling compound Hoechst33258 (Sigma); Amaxa Rat Neuron Nucleofector kit (Lonza, Portsmouth, NH, USA). pcDNA-MT1 and pcDNA-MT2 were kindly provided by Dr Steven Reppert (UMASS Medical School). MT1 cDNA and MT2 cDNA were amplified by PCR. Xhol and Kpnl restriction sites were introduced with the forward and reverse primers, respectively. The reverse

a
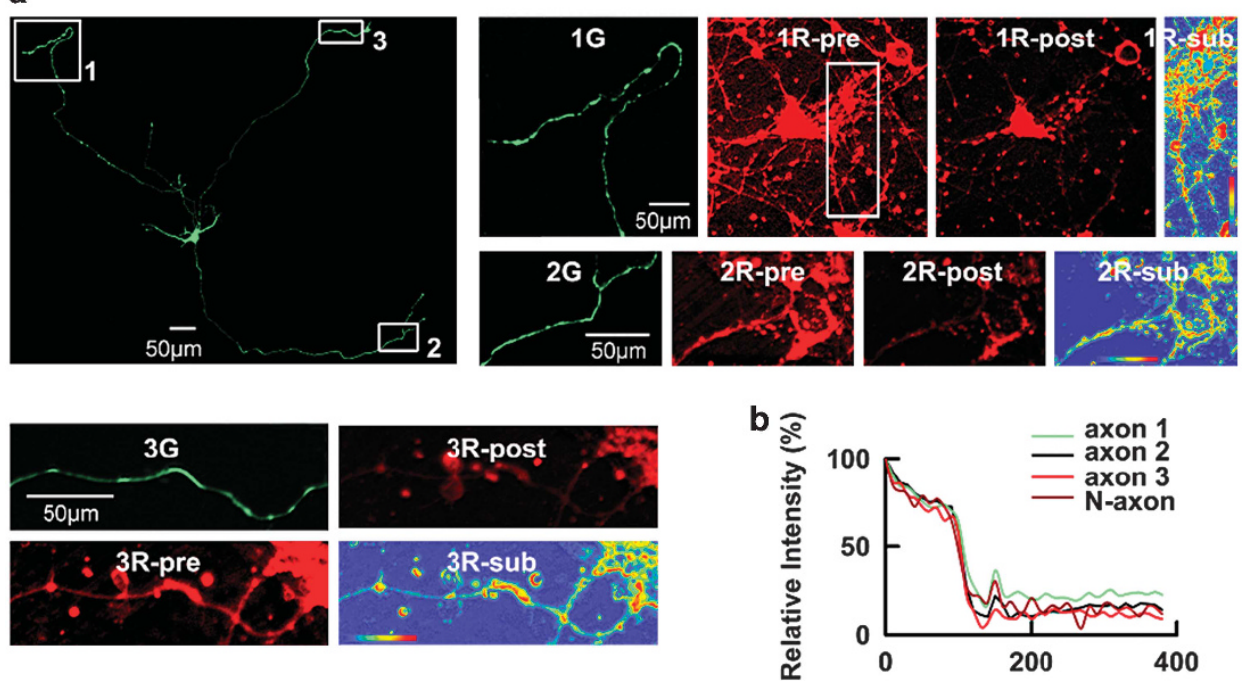

C

DMSO

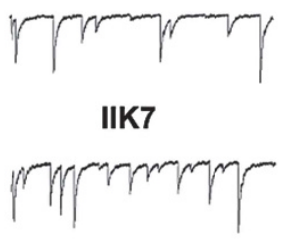
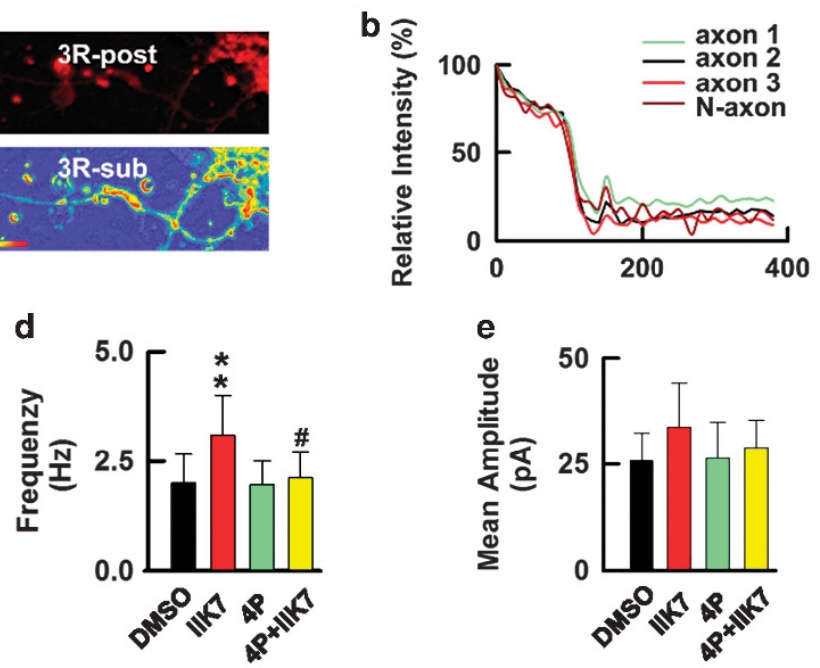

4P

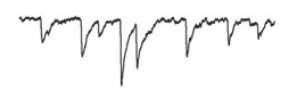

\section{f}
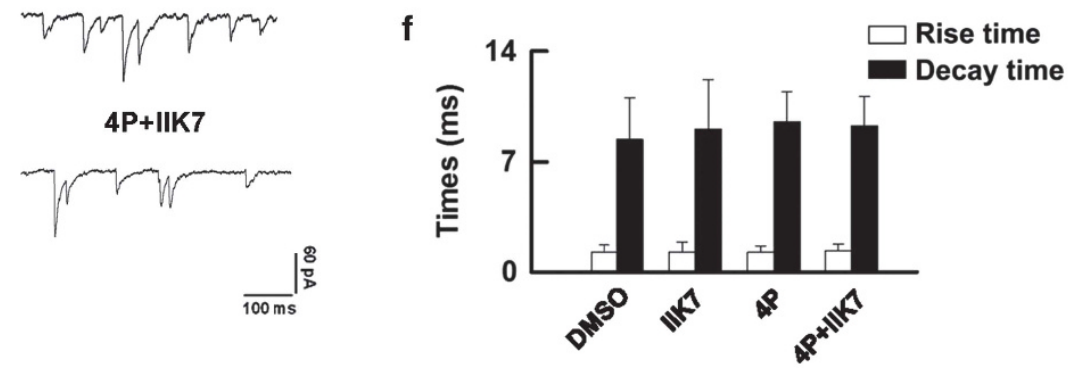

Figure 5 Activation of MT2 receptor induces functional axon formation. (a) Rat neurons were transfected with EGFP (green) at $36 \mathrm{~h}$ and then treated with IIK7 (10 $\mu \mathrm{M})$ at $72 \mathrm{~h}$ for another $120 \mathrm{~h}$, and a representative EGFP-expressing hippocampal neuron showing three axons at 8 div. Boxes 1-3, axon terminals as boxed were loaded with FM4-64 and imaged $100 \mathrm{~s}$ before (pre), and $300 \mathrm{~s}$ after (post) $90 \mathrm{mM} \mathrm{KCl}$ stimulation and subtraction (Sub) indicates the decrements of FM4-64 fluorescence. (b) Kinetics of FM4-64 fluorescence were expressed as relative intensity, in the three individual axons as boxed in (a). N: axon was from an untreated hippocampal neuron. (c-f) Representative recordings of the mEPSCs from the 8 div cultured rat hippocampal neurons treated with DMSO, IIK7 (10 $\mu \mathrm{M})$, 4P-PDOT (4P, $10 \mu \mathrm{M})$, or 4P-PDOT (10 $\mu \mathrm{M})$ plus IIK7 (10 $\mu \mathrm{M})(4 \mathrm{P}$ $+\mathrm{IIK} 7)$ at $72 \mathrm{~h}$ after plating. The frequency and mean amplitude andrise/decay time of the mEPSCs were analyzed $(n=13)$. Data are mean \pm S.E.M. ${ }^{* \star} P<0.01$ versus DMSO, ${ }^{\#} P<0.05$ versus IIK7

Figure 4 Activation of MT2 receptor promotes axon formation during maintainance phase. ( $\mathbf{a}$ and $\mathbf{b}$ ) Rat neurons were transfected with DsRED (red) at $36 \mathrm{~h}$ and then treated with IIK7 $(10 \mu \mathrm{M})$ or DMSO at $72 \mathrm{~h}$ after plating. Seventy-two hours after treatment, time lapse recording was performed. Arrows indicate the time-lapse differentiation of two neurites at $72 \mathrm{~h}$ (a) into neonatal axons at $144 \mathrm{~h}$ (b), as stained with Tau1 (green, boxes 1 and $3 \mathrm{in} \mathbf{b}$ ), while the arrowhead shows the differentiated axon at $72 \mathrm{~h}$ (a) and its Tau1 staining at $144 \mathrm{~h}$ (green, box 2 in b) $(n=75-100)$. (c and d) Rat primary hippocampal neurons were transfected with DsRed (red) at $36 \mathrm{~h}$ after plating and then treated with melatonin (MEL) at $72 \mathrm{~h}$. At $144 \mathrm{~h}$, the axon-dendrite differentiation in the individual neurons was traced by time-lapse recording. Arrow indicates the differentiation of a neurite at $72 \mathrm{~h}(\mathbf{c}$, high magnification in box 1) into axon at $144 \mathrm{~h}$ (d), as stained with Tau1 (green, box 2 in d). Arrowhead indicates the differentiated axon at $72 \mathrm{~h}$ (c, high magnification in box 1) and its Tau1 staining at $144 \mathrm{~h}$ (box 3 in $\mathrm{d}$ ) 
a
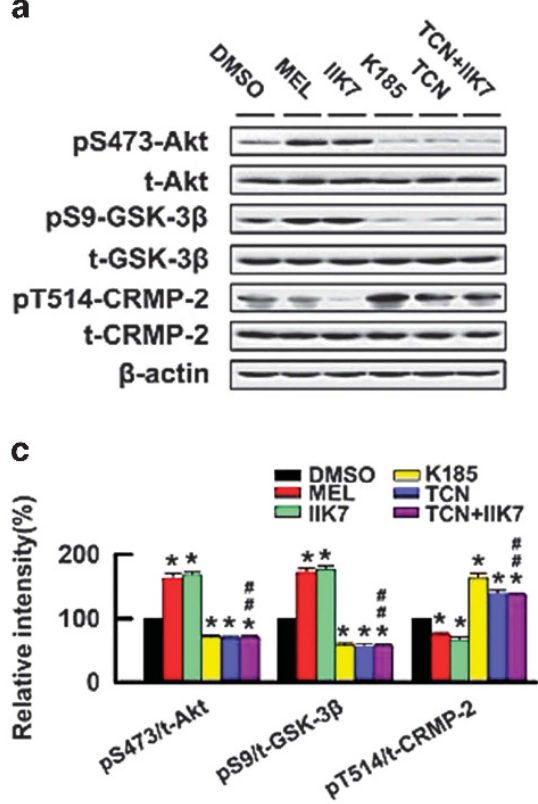

e
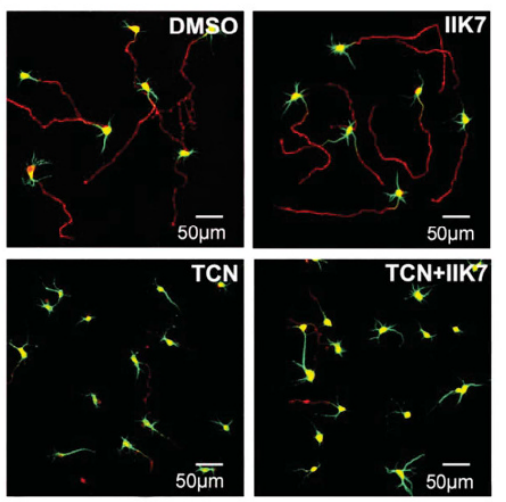

g

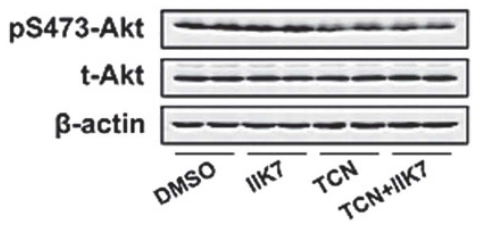

b

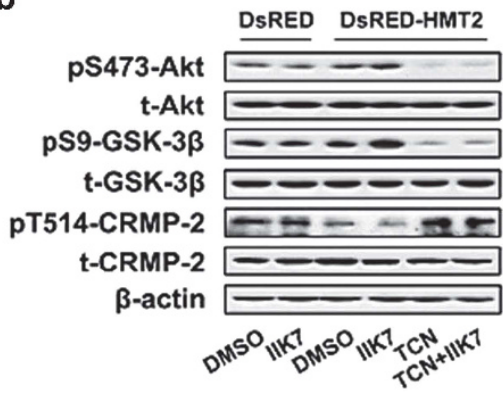

d

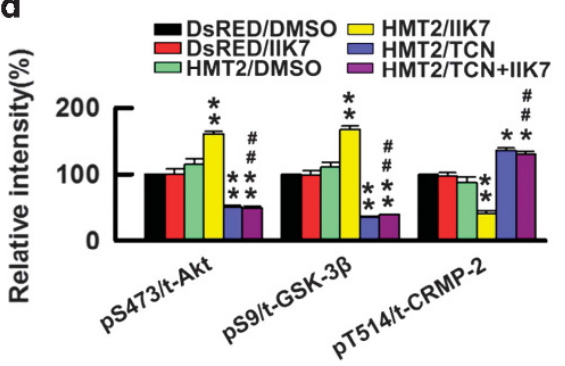

$\mathbf{f}$

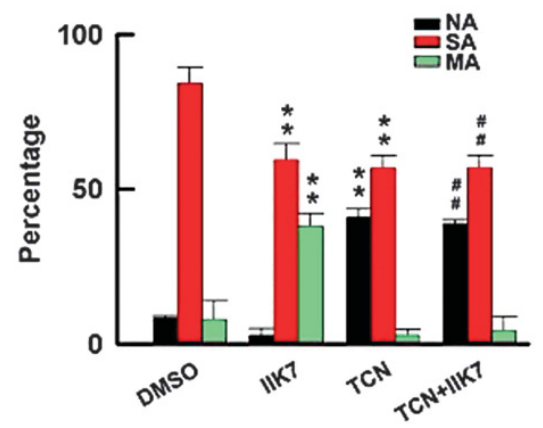

h

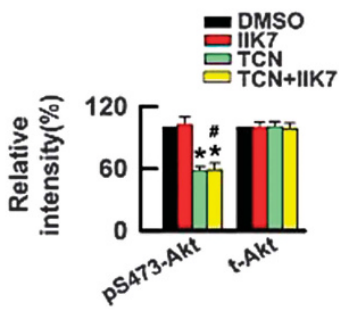

Figure 6 MT2 receptor is linked with Akt/GSK-3//CRMP2 pathway. (a and c) Rat neurons treated with DMSO, MEL (500 $\mu \mathrm{M})$, IIK7 (10 $\mu \mathrm{M}), \mathrm{K} 185$ (10 $\mu \mathrm{M})$, TCN (400 nM), or TCN (400 nM) plus IIK7 $(10 \mu \mathrm{M})(\mathrm{TCN}+$ IIK7) for $2 \mathrm{~h}$, then the protein extracts were examined by western blotting and $\beta$-actin was used as a loading control $(n=3)$. Data are mean \pm S.E.M. ${ }^{*} P<0.05$ versus DMSO; ${ }^{\#} P<0.01$ versus IIK7. (b and d) HEK293 cells co-transfected with DsRED-labeled human MT2 (DsRED-HMT2) or DsRED vector, and treated with DMSO, IIK7 $(10 \mu \mathrm{M})$, TCN $(400 \mathrm{nM})$, or TCN $(400 \mathrm{nM})$ plus IIK7 $(10 \mu \mathrm{M})(\mathrm{TCN}+\mathrm{IIK} 7)$ for $2 \mathrm{~h}$. Then, the protein extracts were examined by western blotting $(n=3)$. Data are mean \pm S.E.M. ${ }^{*} P<0.05,{ }^{* \star} P<0.01$ versus DsRED/DMSO; ${ }^{\# \#} P<0.01$ versus HMT2/IK7. The two-way ANOVA followed by Tukey's test was performed. (e and $\mathrm{f}$ ) Representative images and the quantitative analyses of the hippocampal neuron cultures treated with DMSO, IIK7 (10 $\mu \mathrm{M})$, TCN (400 nM), or TCN (400 nM) plus IIK7 (10 $\mu \mathrm{M})$ (TCN+IIK7), and then co-stained with Tau1 (red) and MAP2 (green) ( $n=62-74)$. Data are mean \pm S.E.M. ${ }^{* *} P<0.01$ versus DMSO; \#\# $P<0.01$ versus IIK7. (g and $\left.\mathbf{h}\right)$ Neurons cultured from MT2 - / - mice were treated with DMSO, IIK7 $(10 \mu \mathrm{M})$, or TCN $(400 \mathrm{nM})$, or TCN $(400 \mathrm{nM})$ plus IIK7 $(10 \mu \mathrm{M})(\mathrm{TCN}+$ IIK7) at $4 \mathrm{~h}$ after plating. The lyses were collected at 3 div for western blot $(n=3)$. Data are mean \pm S.E.M. ${ }^{*} P<0.05$ versus DMSO; ${ }^{\#} P<0.05$ versus IIK7

primer was designed to remove the stop codon. The resultant fragments were inserted into the corresponding sites of pEGFP-N1. EGFP-AktPH and EGFP$A k t P H^{R 25 C}$ mutants were kindly provided by Dr Jong Kyeong Chung (Korea Advanced Institute of Science and Technology). The MT2 - / - mice were kindly gifted by Dr D Weaver at the University of Massachusetts Medical School (USA).
Cell culture, pharmacological treatment, and transfection. Cultures of dissociated hippocampal neurons were prepared from embryonic E18 rats as previously described. ${ }^{29,44}$ The hippocampi of embryos were dissected and trypsinized by TrypLE Express (Invitrogen, Grand Island, NY, USA) for $15 \mathrm{~min}$ at $37^{\circ} \mathrm{C}$. Dissociated neurons were plated onto poly-D-lysine (Sigma) coated 

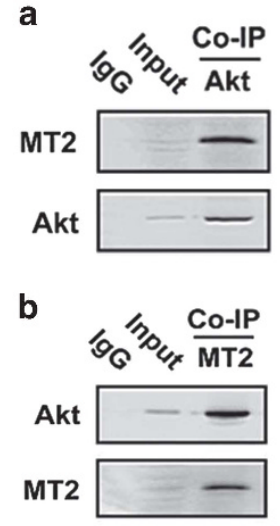

d

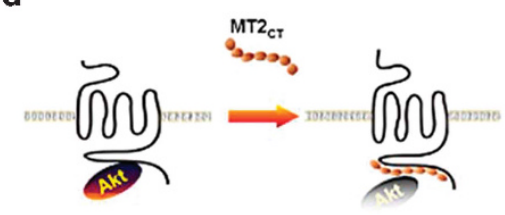

$\mathbf{f}$

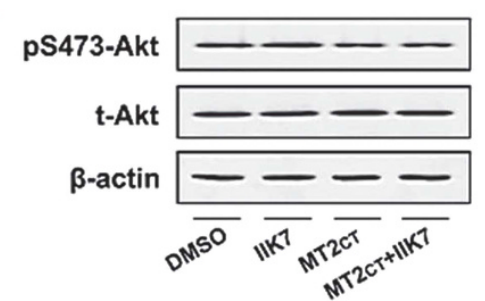

h
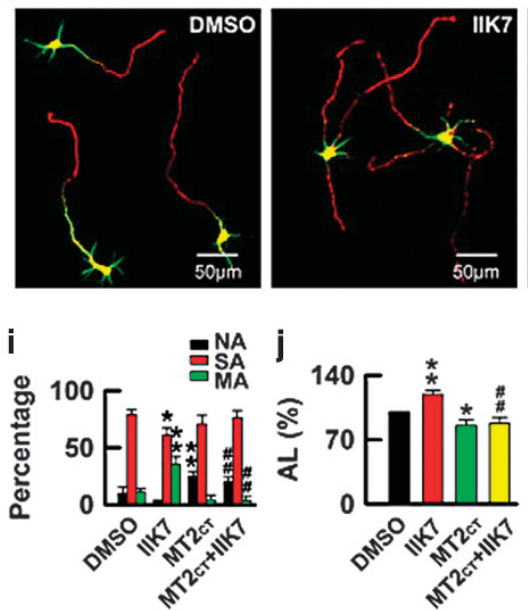

$\mathbf{m}$
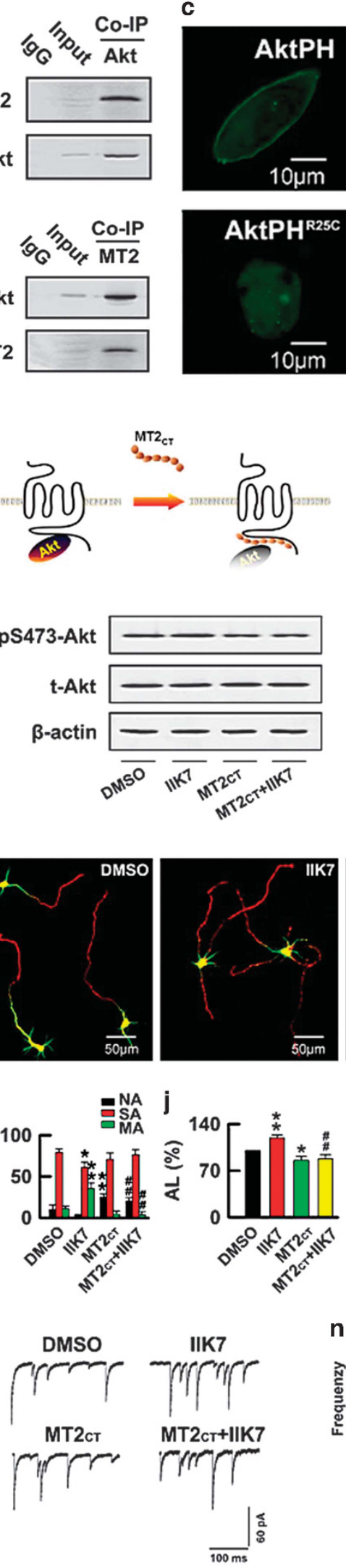
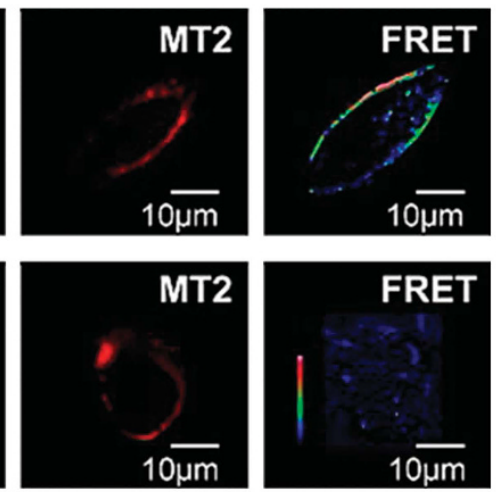

e

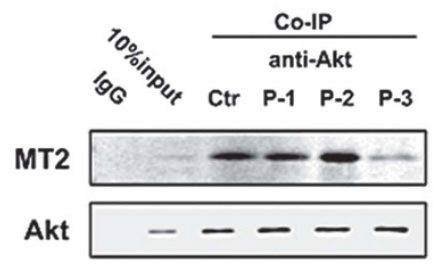

g
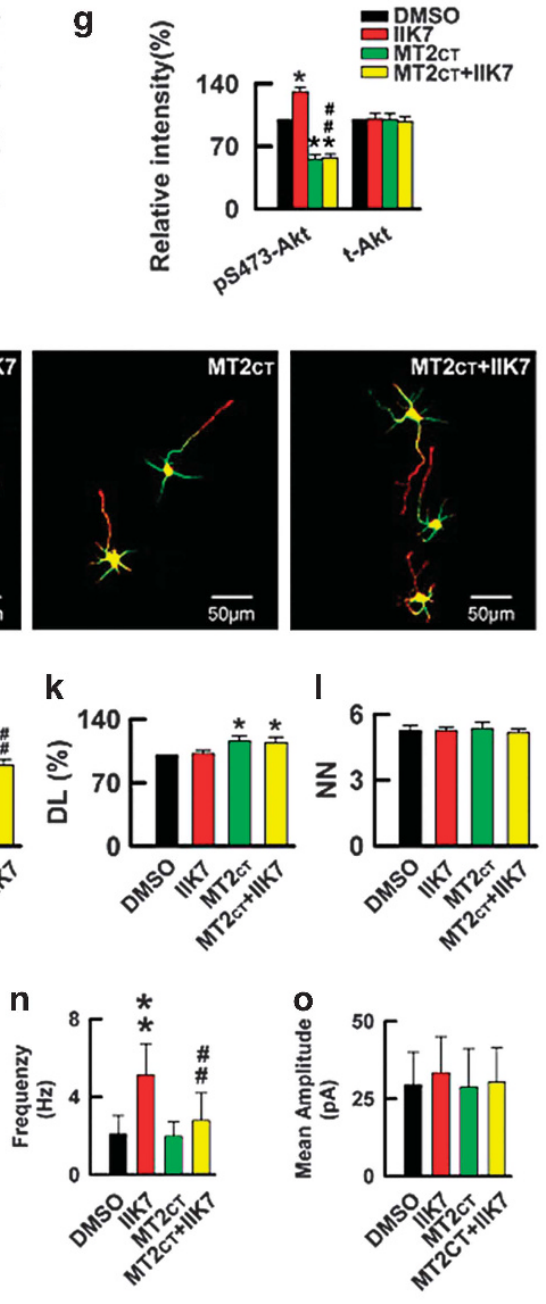

Figure 7 For caption see next page 
coverslips in a 12-well plate or tissue culture dish covered with a glass bottom (WPI) at a higher density $\left(400-600\right.$ neurons $\left./ \mathrm{mm}^{2}\right)$ for transfection and a lower density (100-200 neurons $/ \mathrm{mm}^{2}$ ) for immunofluorescence and pharmacological treatment. Neurons usually attached to the substrate after growing in the plating medium (DMEM/F12 with $10 \%$ fetal bovine serum (FBS) and $100 \mathrm{U} / \mathrm{ml}$ penicillin/ streptomycin) for 2-4 h. Neurobasal medium (Invitrogen) supplemented with $2 \%$ B-27 (Invitrogen) was then replaced after attachment. For immunofluorescence staining, IIK7, K185, Melatonin, 4P-PDOT, TCN, and PKC-Zeta Pseudosubstrate were added directly to neuronal cultures after the medium was changed to Neurobasal medium at $4 \mathrm{~h}$ (for examining the establishment of neuronal polarity) or at 3 div (for examining the maintenance of neuronal polarity) after plating. For western analysis, all drugs were added $2 \mathrm{~h}$ before lysis at 6 div. Neurons were transfected with Lipo2000 (Invitrogen) at $36 \mathrm{~h}$ after plating or by Amaxa Rat Neuron Nucleofector kit before plating. HEK293 cells were grown in DMEM supplemented with 10\% FBS and transiently transfected using Lip02000. IIK7 and TCN were treated for 2 at $48 \mathrm{~h}$ after HEK 293 transfection.
Immunofluorescence and data analysis. For immunofluorescence staining, neurons were cultured on coverslips in 12-well plate for 3 div (establishment of neuronal polarity) or 6 div (maintenance of neuronal polarity). For in vivo studies, brains were fixed by transcardial perfusion of $4 \%$ paraformaldehyde and sectioned coronally. Cultured neurons or brain sections were immunostained by previously described methods. ${ }^{29,44}$ Neurons and brain sections were incubated in primary antibodies for $12-36 \mathrm{~h}$ at $4{ }^{\circ} \mathrm{C}$ and subsequently with AlexaFluro 488 - and AlexaFluro 546-conjugated secondary antibodies. Images were examined by using a Zeiss LSM510 laser confocal microscope (Zeiss, Jena, Germany) or an Olympus IX70 fluorescence microscope (Olympus, Tokyo, Japan). Neurons were categorized into three phenotypes: single axon (SA), multiple axons (MA), and no axon (NA). In most cases, the axon was defined by axon-specific immunostaining of Tau1. Neurite length was also used in some cases for assessing axon differentiation by the following criteria: a process at least twice as long as the other processes and longer than $180 \mu \mathrm{m}$ ( $3 \mathrm{div}$ ) and the other processes were defined as dendrites. ${ }^{35,58}$ The length of neurites was determined using the Zeiss LSM image examiner software (Zeiss). The

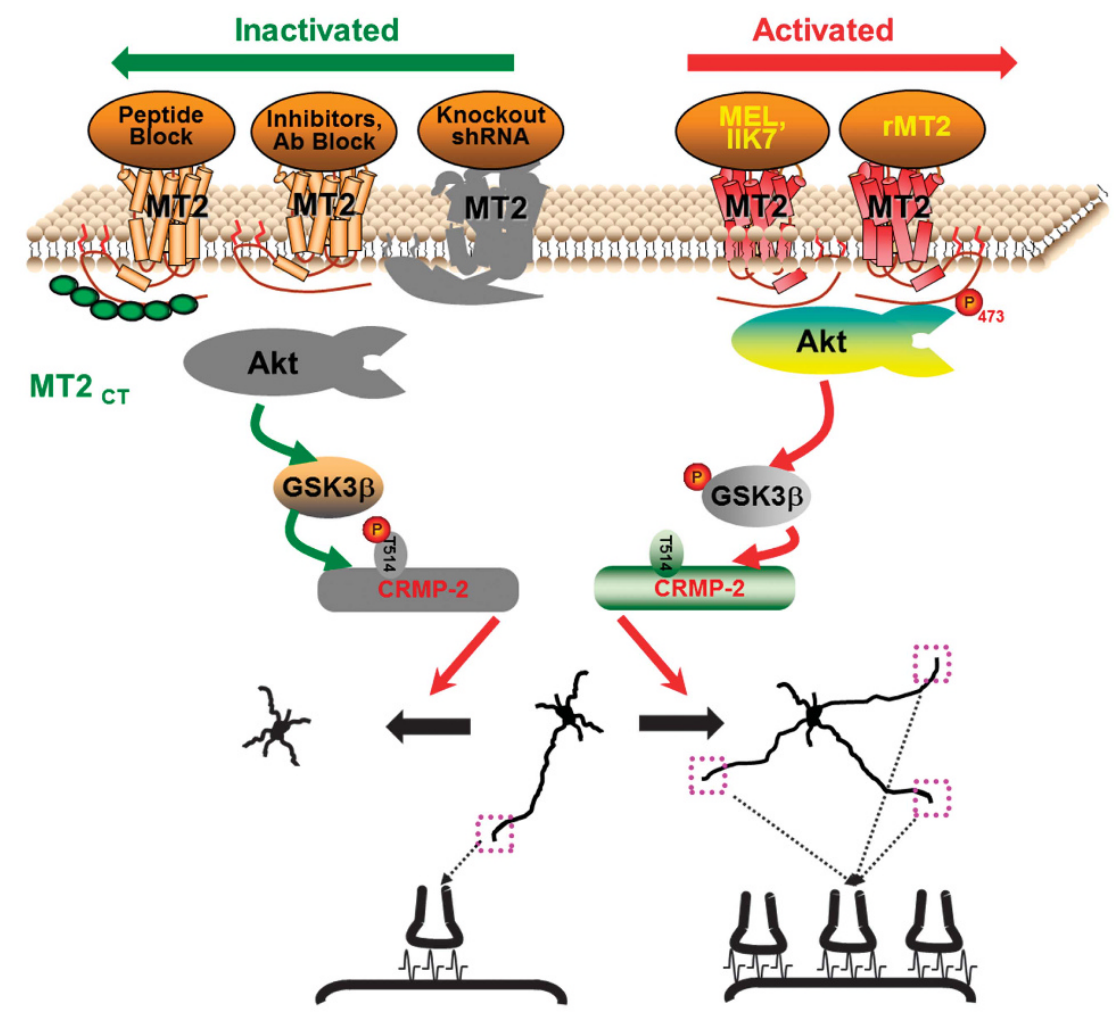

Figure 8 Schematics show the promoting role of MT2 in axonogenesis and synaptic potentiation. Activation of MT2 by melatonin (MEL), IIK7 or MT2 overexpression can stimulate a direct association of MT2 with Akt, which in turn initiate Akt/GSK-3//CRMP-2 signaling pathway, promote formation of multiple functional axons and potentiate synaptic transmission. On the contrary, inhibition of MT2 signaling by specific inhibitors such as 4P-PDOT and K185, antibody blockage, genetic knockout, or membranous permeable peptide suppresses the axonogenesis and synaptic transmission

Figure 7 Disruption of MT2-Akt direct interaction inhibits axon differentiation and synaptic formation. (a and $\mathbf{b})$ Hippocampal extracts from E18 rat embryos were immunoprecipitated with MT2 or Akt antibody, and probed by western blotting as labeled. (c) HEK293 cells were co-transfected with DsRED-HMT2 (red) and Akt PH domain (AktPH, green) or Akt PH R25C mutant (AktPH ${ }^{\mathrm{R} 25 \mathrm{C}}$, green), acceptor photobleaching FRET was performed to analyze the interaction of MT2 and Akt PH domain. (d) Illustration shows that application of $10 \mu \mathrm{M}$ MT2 C-terminal peptide (MT2 $\mathrm{CT}$ ) disrupts MT2-Akt interaction. (e) The E18 rat hippocampal extracts were incubated with $10 \mu \mathrm{M}$ control peptide (Ctr) or MT2 $\mathrm{Cr}$ peptides (P-1, P-2, and P-3) for $30 \mathrm{~min}$ at $37^{\circ} \mathrm{C}$, and then the extracts were immunoprecipitated with anti-Akt and blotted with MT2 and Akt. (f and $\mathbf{g}$ ) Rat hippocampal neurons were incubated with DMSO, IIK7 $(10 \mu \mathrm{M})$, MT2 $\mathrm{CT}(\mathrm{P}-3,10 \mu \mathrm{M})$, or MT2 $\mathrm{CT}_{\mathrm{CT}}(10 \mu \mathrm{M})$ plus IIK7 $(10 \mu \mathrm{M})\left(\mathrm{MT} 2_{\mathrm{CT}}+\mathrm{llK} 7\right)$ for $1 \mathrm{~h}$, then t-Akt and p473-Akt were analyzed by quantitative western blotting. ( $n=3$ ) Data are mean \pm S.E.M. ${ }^{*} P<0.05$ versus DMSO; \#\# $P<0.01$ versus IIK7. (h) Dissociated rat hippocampal neurons (E18) were treated with DMSO, IIK7 $(10 \mu \mathrm{M})$, MT2 $\mathrm{CT}(\mathrm{P}-3,10 \mu \mathrm{M})$, or MT2 $2_{\mathrm{CT}}(10 \mu \mathrm{M})$ plus IIK7 $(10 \mu \mathrm{M})\left(\mathrm{MT} 2_{\mathrm{CT}}+\mathrm{IIK} 7\right)$ at $4 \mathrm{~h}$ after plating. Seventy-two hours after plating, the cultures were co-stained with Tau1 (red) and MAP2 (green) ( $n=76-84)$. (i-I) Bar graphs show the percentage of no-axon (NA), single-axon (SA), and multiple-axon (MA) neurons, as well as axon length (AL), dendrite length (DL), and the neurite number (NN). Data are mean \pm S.E.M. ${ }^{*} P<0.05,{ }^{* \star} P<0.01$ versus DMSO; ${ }^{\# \#} P<0.01$ versus IIK7. (m) Representative recordings of the mEPSCs from the 8 div cultured rat hippocampal neurons treated with DMSO, IIK7 (10 $\mu \mathrm{M})$, MT2 $2_{\mathrm{CT}}(10 \mu \mathrm{M})$, or MT2 $\mathrm{CT}(10 \mu \mathrm{M})$ plus IIK7 (10 $\left.\mu \mathrm{M}\right)\left(\mathrm{MT} 2_{\mathrm{CT}}+\mathrm{IIK} 7\right)$ at $72 \mathrm{~h}$ after plating. ( $\mathrm{n}$ and $\mathbf{o})$ Bar graphs show the frequency and mean amplitude of the mEPSCs $(n=11)$. Data are mean \pm S.E.M. ${ }^{* *} P<0.01$ versus DMSO, ${ }^{\# \#} P<0.01$, versus IIKT 
intensity of fluorescence was analyzed by using the NIH Image J software (Bethesda, MD, USA) according to the published methods. ${ }^{59}$

Western blotting. The western blotting was carried out by a well-established procedure in our laboratory. ${ }^{29,44}$ Briefly, the cell extracts prepared from HEK 293 or cultured neurons were separated by SDS-PAGE $(10 \%)$ and the proteins were transferred onto nitrocellulose membrane (Amersham, Piscataway, NJ, USA) for $1 \mathrm{~h}$ using the transfer apparatus (Bio-Rad, Berkeley, CA, USA). After block with $3 \%$ milk for $30 \mathrm{~min}$ at room temperature, the membranes were then incubated at $4{ }^{\circ} \mathrm{C}$ with primary antibodies overnight. The blots were probed by using IRDye $800 \mathrm{CW}$ conjugated secondary antibody and visualized by infrared fluorescence imaging. The intensity of the protein bands was quantified by using the enhanced chemiluminescence (ECL) or Odyssey system (Li-Cor Bioscience, Lincoln, NE, USA). The protein concentration was estimated by using the BCA kit (Pierce, Rockford, IL, USA).

In utero electroporation. The shRNA constructs were introduced into the lateral ventricle at E15.5-16.5 and specifically targeted into forebrain pyramidal neurons by using in utero electroporation as previously described. ${ }^{44}$ Briefly, after anesthetization, the abdominal cavity was opened, and the uterine horns were exposed. Constructs with mU6-MT2-shRNA-pUbi-EGFP or the scrambled shRNA (Genechem Inc., Shanghai, China, $3 \mu \mathrm{g}$ in $2 \mu \mathrm{l}$ ) were injected through a glass micropipette into the lateral ventricle of the embryos. Electroporation (50-ms square pulses of $50 \mathrm{~V}$ at 100-ms intervals; 5 times) was then carried out using an Electro Square Porator (CUY21Edit, Nepagene, Chiba). The pups were perfused with $4 \%$ paraformaldehyde at postnatal day $0(\mathrm{PO})$ or day $3(\mathrm{P} 3)$, and then the brains were harvested and fixed in $4 \%$ paraformaldehyde for $2 \mathrm{~h}$ at $4{ }^{\circ} \mathrm{C}$, and cryoprotected in $30 \%$ sucrose overnight. Thereafter, the brain was embedded in OCT compound (Sakura Finetek Europe, Zoeterwoude, Alphen aan den Rijn, Netherland) and frozen in dry ice. Coronal cryosections $(35 \mu \mathrm{m})$ were made and examined by confocal microscopy. The methods for neuronal migration detection were used as previously reported. ${ }^{60,61}$ Briefly, coronal brain sections at the same layer of different treatments (scrambled or si-MT2) were examined by confocal microscopy by using a $488 \mathrm{~nm}$ laser to excite the GFP and the images were captured automatically by the LSM710 software (Zeiss). Then, the slices were divided into five layers according to the previous reports. MZ marginal zone; CP, cortical plate; SP, subplate; IZ, intermediate zone; SVZ, subventricular zone. And the numbers of neurons in different layers were counted to calculate the percentages for evaluating the neuronal migration.

FM4-64 staining. The uptake and release function of the neurons was measured by using FM4-64 staining experiments on an inverted microscope with $40 \times$ objectives (LSM510 Zeiss Axiovert $200 \mathrm{~m}$, Zeiss). Neurons cultured in a tissue culture dish with coverglass bottom at 8 div were loaded with $10 \mu \mathrm{M}$ FM4-64 in solution containing $45 \mathrm{mM} \mathrm{K}^{+}$for $1 \mathrm{~min}$, and then washed with solution containing $3 \mathrm{mM} \mathrm{K}^{+}$for $15 \mathrm{~min}$. After collecting FM fluorescent images, the same live neurons were subjected to $90 \mathrm{mM} \mathrm{K}^{+}$solution for $5 \mathrm{~min}$ to evaluate the release function of the neurons.

Acceptor photobleaching FRET. FRET was quantified on the basis of the acceptor photobleaching method, developed for a Zeiss LSM510 laser-scanning confocal microscopy. HEK293 cells were co-transfected with EGFP-AktPH or EGFP-AktPH R25C with DsRED-labeled human MT2 (DsRED-HMT2, 1:3). Conventional fluorescence microscopy was used to confirm fluorescence protein expression 24-48 $\mathrm{h}$ after the transfection, and then cells were re-fed with serumfree DMEM before being imaged by confocal microscopy. For donor imaging, the GFP filter was set to $488 \mathrm{~nm}$ for excitation and emission at $518 / 12 \mathrm{~nm}$, while the DsRED filter was set to $543 \mathrm{~nm}$ for excitation and emission at $585 / 30 \mathrm{~nm}$ for acceptor imaging. Images were created with a resolution of $512 \times 512$ pixels per inch. Cells with low to moderate expression levels of both EGFP and DsRED-fusion proteins were selected. To produce non-saturating fluorescence, the cells were first pre-scanned with a suitable laser intensity and voltage, and then images of the donor and acceptor were taken simultaneously. To detect FRET, cells with a similar fluorescence intensity ratio of donor/acceptor were chosen and regions of interest (ROI1) within the fluorescence-expressing area of the nucleus were selected for photobleaching. In the same nuclei, a region with the similar fluorescence intensity as ROI1 was chosen as the unbleached control, ROI2. Seven pre-bleach images were taken first, then the ROl1 was bleached with the maximum $543 \mathrm{~nm}$ lasers for 6-10 iterations, and seven post-bleach images of the donor and acceptor were captured finally under the same conditions as those for the pre-bleach images. Fluorescence intensity of the selected $\mathrm{ROI}$ was quantified at each time point by Zeiss LSM510 (Zeiss).
Electrophysiology. Cultures of cortical neurons were prepared from embryonic E18 mice. Cells were dissociated and purified using a papain dissociation kit (Worthington Biochemical Corporation, Lakewood Township, NJ, USA) plated with a lower density of $100-200$ neurons $/ \mathrm{mm}^{2}$ onto $12 \mathrm{~mm}$ coverslips coated with $100 \mu \mathrm{g} / \mathrm{ml}$ poly-L-lysine (Sigma) and $20 \mu \mathrm{g} / \mathrm{ml}$ laminin (Invitrogen). Cells were placed in fresh serum-free Neurobasal Medium (21103, GIBCO, Grand Island, NY, USA) plus 2\% B27 (Invitrogen) and fed every 4 days with fresh media. In all, $10 \mu \mathrm{M}$ IIK7 (Sigma) or $30 \mu \mathrm{M}$ MT2 ${ }_{\mathrm{CT}}$ was added directly to neuronal cultures at 3 div after plating. Whole-cell patch clamp recordings were performed after 8 days $(8$ div). Cells were then placed in a recording chamber at room temperature and continually perfused at $2 \mathrm{ml} / \mathrm{min}$ with artificial cerebrospinal fluid (aCSF) containing (in $\mathrm{mM}$ ): $125 \mathrm{NaCl}, 5.4 \mathrm{KCl}, 20$ HEPES, 15 Glucose, $1.2 \mathrm{MgCl}_{2}, 2 \mathrm{CaCl}_{2}$ (pH 7.35, $300 \mathrm{mOsm})$. Patch electrodes (3-5 MG) were filled with an internal solution containing (in $\mathrm{mM}$ ): 130 potassium gluconic acid, $12 \mathrm{KCl}, 10$ HEPES, 0.2 EGTA, 2 MgATP, $0.3 \mathrm{Li}_{2} \mathrm{GTP}, 5 \mathrm{QX} 314$ (pH 7.32, $287 \mathrm{mOsm}$ ). AMPAR-mediated mEPSCs were measured with a gap-free model and analyzed using Clamp fit 10.2 (Axon Instruments, Union City, CA, USA).

Statistical analysis. Data were analyzed using the SPSS 11.0 statistical software (SPSS Inc., Chicago, IL, USA), and the one-way ANOVA procedure followed by Tukey's tests was used to determine the differences between the groups if not specifically described.

\section{Conflict of Interest}

The authors declare no conflict of interest.

Acknowledgements. We thank $\operatorname{Dr} D$ Weaver at University of Massachusetts Medical School (USA) for MT2 knockout mice. Drs K Kaibuchi and T Yoshimura at Nagoya University (Japan) for pT514-CRMP-2 antibody and CRMP-2 plasmids. Dr S Reppert at University of Massachusetts Medical School (USA) for human MT2 and MT1 plasmid. Dr J Chung at Korea Advanced Institute of Science and Technology for EGFP-AktPH and EGFP-AktPHR25C plasmids. Dr H Ishii at Nippon Medical School for the rat MT1 and rat MT2 plasmids. We thank James Gilbert at Boston University for assistance in manuscript preparation. This work was supported in parts by the National Natural Science Foundation of China (81261120570, 91132725, $81361120245,81130079,31201011,81428009,91132305)$, the Ministry of Science and Technology of China (2011DFG33250), the National Natural Science Foundation of Hubei Province (2014CFA017).

\section{Author contributions}

LQZ initiated, designed the study; YML supervised the study; DL and NW cultured the neurons, transgenic mice, performed the immunostaining, western blot and immunoprecipitation; LQZ performed FM4-64 recording and FRET; HYM conducted the electrophysiological recordings on neuronal cultures; DL, LQZ, YML and JZW analyzed the data. LQZ, YML and JZW wrote the manuscript.

1. Polleux F, Ince-Dunn G, Ghosh A. Transcriptional regulation of vertebrate axon guidance and synapse formation. Nat Rev Neurosci 2007; 8: 331-340.

2. Bradke F, Dotti CG. The role of local actin instability in axon formation. Science 1999; 283 : 1931-1934.

3. Schwamborn JC, Muller M, Becker AH, Puschel AW. Ubiquitination of the GTPase Rap1B by the ubiquitin ligase Smurf2 is required for the establishment of neuronal polarity. EMBO J 2007; 26: 1410-1422

4. Song $A H$, Wang D, Chen G, Li Y, Luo J, Duan $S$ et al. A selective filter for cytoplasmic transport at the axon initial segment. Cell 2009; 136: 1148-1160.

5. Ozdinler PH, Macklis JD. IGF-I specifically enhances axon outgrowth of corticospinal motor neurons. Nat Neurosci 2006; 9: 1371-1381.

6. Dalva MB, Takasu MA, Lin MZ, Shamah SM, Hu L, Gale NW et al. EphB receptors interact with NMDA receptors and regulate excitatory synapse formation. Cell 2000; 103: 945-956.

7. Pandi-Perumal SR, Trakht I, Srinivasan V, Spence DW, Maestroni GJ, Zisapel N et al. Physiological effects of melatonin: role of melatonin receptors and signal transduction pathways. Prog Neurobiol 2008; 85: 335-353.

8. Ochoa-Sanchez R, Comai S, Lacoste B, Bambico FR, Dominguez-Lopez S, Spadoni G et al. Promotion of non-rapid eye movement sleep and activation of reticular thalamic neurons by a novel MT2 melatonin receptor ligand. J Neurosci 2011; 31: 18439-18452.

9. Comai S, Ochoa-Sanchez R, Gobbi G. Sleep-wake characterization of double MT(1)/MT(2) receptor knockout mice and comparison with $\mathrm{MT}(1)$ and $\mathrm{MT}(2)$ receptor knockout mice. Behav Brain Res 2013; 243: 231-238. 
10. Dubocovich ML, Masana Ml, lacob S, Sauri DM. Melatonin receptor antagonists that differentiate between the human Mel1a and Mel1b recombinant subtypes are used to assess the pharmacological profile of the rabbit retina ML1 presynaptic heteroreceptor. Naunyn-Schmiedeberg's Arch Pharmacol 1997; 355: 365-375.

11. Lankford KL, DeMello FG, Klein WL. D1-type dopamine receptors inhibit growth cone motility in cultured retina neurons: evidence that neurotransmitters act as morphogenic growth regulators in the developing central nervous system. Proc Natl Acad Sci USA 1988; 85: 4567-4571

12. Larson J, Jessen RE, Uz T, Arslan AD, Kurtuncu M, Imbesi M et al. Impaired hippocampal longterm potentiation in melatonin MT2 receptor-deficient mice. Neurosci Lett 2006; 393: 23-26.

13. Wan Q, Man HY, Liu F, Braunton J, Niznik HB, Pang SF et al. Differential modulation of GABAA receptor function by Mel1a and Mel1b receptors. Nat Neurosci 1999; 2: 401-403.

14. Savaskan E, Ayoub MA, Ravid R, Angeloni D, Fraschini F, Meier F et al. Reduced hippocampal MT2 melatonin receptor expression in Alzheimer's disease. J Pineal Res 2005 38: 10-16.

15. Comai S, Gobbi G. Unveiling the role of melatonin MT2 receptors in sleep, anxiety and other neuropsychiatric diseases: a novel target in psychopharmacology. J Psychiatry Neurosci 2014; 39: 6-21.

16. Ochoa-Sanchez R, Rainer Q, Comai S, Spadoni G, Bedini A, Rivara S et al. Anxiolytic effects of the melatonin MT(2) receptor partial agonist UCM765: comparison with melatonin and diazepam. Prog Neuropsychopharmacol Biol Psychiatry 2012; 39: 318-325.

17. Gumuslu E, Mutlu O, Sunnetci D, Ulak G, Celikyurt IK, Cine N et al. The antidepressant agomelatine improves memory deterioration and upregulates CREB and BDNF gene expression levels in unpredictable chronic mild stress (UCMS)-exposed mice. Drug Target Insights 2014; 8: 11-21.

18. Kaech S, Banker G. Culturing hippocampal neurons. Nat Protoc 2006; 1: 2406-2415.

19. Dotti CG, Sullivan CA, Banker GA. The establishment of polarity by hippocampal neurons in culture. J Neurosci 1988; 8: 1454-1468.

20. Barnes AP, Polleux F. Establishment of axon-dendrite polarity in developing neurons. Annu Rev Neurosci 2009; 32: 347-381.

21. Dotti CG, Banker GA. Experimentally induced alteration in the polarity of developing neurons. Nature 1987; 330: 254-256.

22. Jepsen K, Hermanson O, Onami TM, Gleiberman AS, Lunyak V, McEvilly RJ et al. Combinatorial roles of the nuclear receptor corepressor in transcription and development. Cell 2000; 102: 753-763.

23. Shelly M, Cancedda L, Heilshorn S, Sumbre G, Poo MM. LKB1/STRAD promotes axon initiation during neuronal polarization. Cell 2007; 129: 565-577.

24. Hatanaka $Y$, Murakami $F$. In vitro analysis of the origin, migratory behavior, and maturation of cortical pyramidal cells. J Comp Neurol 2002; 454: 1-14.

25. Noctor SC, Martinez-Cerdeno V, Ivic L, Kriegstein AR. Cortical neurons arise in symmetric and asymmetric division zones and migrate through specific phases. Nat Neurosci 2004; 7 : 136-144.

26. Craig AM, Graf ER, Linhoff MW. How to build a central synapse: clues from cell culture. Trends Neurosci 2006; 29: 8-20.

27. Ryan TA, Reuter H, Wendland B, Schweizer FE, Tsien RW, Smith SJ. The kinetics of synaptic vesicle recycling measured at single presynaptic boutons. Neuron 1993; 11: 713-724.

28. Matteoli M, Takei K, Perin MS, Sudhof TC, De Camilli P. Exo-endocytotic recycling of synaptic vesicles in developing processes of cultured hippocampal neurons. J Cell Biol 1992; 117: 849-861.

29. Zhu LQ, Liu D, Hu J, Cheng J, Wang SH, Wang $Q$ et al. GSK-3 beta inhibits presynaptic vesicle exocytosis by phosphorylating P/Q-type calcium channel and interrupting SNARE complex formation. J Neurosci 2010; 30: 3624-3633.

30. Yoshimura T, Kawano Y, Arimura N, Kawabata S, Kikuchi A, Kaibuchi K. GSK-3beta regulates phosphorylation of CRMP-2 and neuronal polarity. Cell 2005; 120: 137-149.

31. Chi XX, Schmutzler BS, Brittain JM, Wang Y, Hingtgen CM, Nicol GD et al. Regulation of N-type voltage-gated calcium channels (Cav2.2) and transmitter release by collapsin response mediator protein-2 (CRMP-2) in sensory neurons. J Cell Sci 2009; 122 4351-4362.

32. Peineau S, Bradley C, Taghibiglou C, Doherty A, Bortolotto ZA, Wang YT et al. The role of GSK-3 in synaptic plasticity. Br J Pharmacol 2008; 153: S428-S437.

33. Jiang $\mathrm{H}$, Guo W, Liang $\mathrm{X}$, Rao Y. Both the establishment and the maintenance of neuronal polarity require active mechanisms: critical roles of GSK-3beta and its upstream regulators Cell 2005; 120: 123-135.

34. Cole AR, Knebel A, Morrice NA, Robertson LA, Irving AJ, Connolly CN et al. GSK-3 phosphorylation of the Alzheimer epitope within collapsin response mediator proteins regulates axon elongation in primary neurons. J Biol Chem 2004; 279: 50176-50180.
35. Shi SH, Jan LY, Jan YN. Hippocampal neuronal polarity specified by spatially localized $\mathrm{mPar3/mPar6}$ and PI 3-kinase activity. Cell 2003; 112: 63-75.

36. Bockaert J, Roussignol G, Becamel C, Gavarini S, Joubert L, Dumuis A et al. GPCRinteracting proteins (GIPs): nature and functions. Biochem Soc Trans 2004; 32: 851-855.

37. Brydon L, Petit L, Delagrange P, Strosberg AD, Jockers R. Functional expression of MT2 (Mel1b) melatonin receptors in human PAZ6 adipocytes. Endocrinology 2001; 142: 4264-4271.

38. Shelly M, Lim BK, Cancedda L, Heilshorn SC, Gao H, Poo MM. Local and long-range reciprocal regulation of CAMP and CGMP in axon/dendrite formation. Science 2010; 327: 547-552.

39. Beaulieu JM, Sotnikova TD, Marion S, Lefkowitz RJ, Gainetdinov RR, Caron MG. An Akt/ beta-arrestin 2/PP2A signaling complex mediates dopaminergic neurotransmission and behavior. Cell 2005; 122: 261-273.

40. Du K, Tsichlis PN. Regulation of the Akt kinase by interacting proteins. Oncogene 2005; 24 7401-7409.

41. Reddy $\mathrm{PH}$. Abnormal tau, mitochondrial dysfunction, impaired axonal transport of mitochondria, and synaptic deprivation in Alzheimer's disease. Brain Res 2011; 1415 136-148.

42. Rossi F, Gianola S, Corvetti L. Regulation of intrinsic neuronal properties for axon growth and regeneration. Prog Neurobiol 2007; 81: 1-28.

43. Deumens R, Koopmans GC, Joosten EA. Regeneration of descending axon tracts after spinal cord injury. Prog Neurobiol 2005; 77: 57-89.

44. Zhu LQ, Zheng HY, Peng CX, Liu D, Li HL, Wang Q et al. Protein phosphatase $2 A$ facilitates axonogenesis by dephosphorylating CRMP2. J Neurosci 2010; 30: 3839-3848.

45. Peng CX, Hu J, Liu D, Hong XP, Wu YY, Zhu LQ et al. Disease-modified glycogen synthase kinase-3beta intervention by melatonin arrests the pathology and memory deficits in an Alzheimer's animal model. Neurobiol Aging 2013; 34: 1555-1563.

46. Bahna SG, Sathiyapalan A, Foster JA, Niles LP. Regional upregulation of hippocampa melatonin MT2 receptors by valproic acid: therapeutic implications for Alzheimer's disease. Neurosci Lett 2014; 576: 84-87.

47. luvone PM, Gan J. Functional interaction of melatonin receptors and D1 dopamine receptors in cultured chick retinal neurons. J Neurosci 1995; 15: 2179-2185.

48. Witt-Enderby PA, Bennett J, Jarzynka MJ, Firestine S, Melan MA. Melatonin receptors and their regulation: biochemical and structural mechanisms. Life Sci 2003; 72: 2183-2198.

49. Catala MD, Quay WB, Timiras PS. Effects of thyroid hormone on light/dark melatonin synthesis and release by young and maturing rat pineal glands in vitro. Int J Dev Neurosci 1988; 6: 285-288

50. Drijfhout WJ, Grol CJ, Westerink BH. Parasympathetic inhibition of pineal indole metabolism by prejunctional modulation of noradrenaline release. Eur J Pharmacol 1996; 308: 117-124.

51. Yamada H, Yatsushiro S, Ishio S, Hayashi M, Nishi T, Yamamoto A et al. Metabotropic glutamate receptors negatively regulate melatonin synthesis in rat pinealocytes. J Neurosci 1998; 18: 2056-2062.

52. Foldes A, Maxwell CA, Rintoul AJ, Edols RW. Sheep pineal beta-adrenoceptor function-interaction with gamma-aminobutyric acid. Neuroendocrinology 1984; 38: 206-211.

53. Simonneaux V, Ribelayga C. Generation of the melatonin endocrine message in mammals: a review of the complex regulation of melatonin synthesis by norepinephrine, peptides, and other pineal transmitters. Pharmacol Rev 2003; 55: 325-395.

54. Liu F, Day M, Muniz LC, Bitran D, Arias R, Revilla-Sanchez R et al. Activation of estrogen receptor-beta regulates hippocampal synaptic plasticity and improves memory. Nat Neurosci 2008; 11: 334-343.

55. Bernal J. Thyroid hormone receptors in brain development and function. Nat Clin Pract Endocrinol Metab 2007; 3: 249-259.

56. McCarthy MM. Estradiol and the developing brain. Physiol Rev 2008; 88: 91-124.

57. Spencer GE, Klumperman J, Syed NI. Neurotransmitters and neurodevelopment. Role of dopamine in neurite outgrowth, target selection and specific synapse formation. Perspect Dev Neurobiol 1998; 5: 451-467.

58. Ruthel G, Hollenbeck PJ. Growth cones are not required for initial establishment of polarity or differential axon branch growth in cultured hippocampal neurons. J Neurosci 2000; 20: 2266-2274.

59. Jensen EC. Quantitative analysis of histological staining and fluorescence using ImageJ. Anat Rec 2013; 296: 378-381.

60. Takeuchi A, O'Leary DD. Radial migration of superficial layer cortical neurons controlled by novel Ig cell adhesion molecule MDGA1. J Neurosci 2006; 26: 4460-4464.

61. Tabata $\mathrm{H}$, Nakajima K. Efficient in utero gene transfer system to the developing mouse brain using electroporation: visualization of neuronal migration in the developing cortex Neuroscience 2001; 103: 865-872.

\section{Supplementary Information accompanies this paper on Cell Death and Differentiation website (http://www.nature.com/cdd)}

